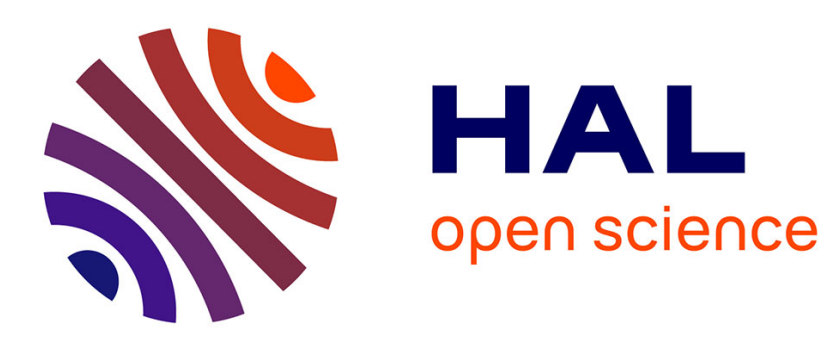

\title{
The Native Mind: Biological Categorization and Reasoning in Development and Across Cultures
}

\author{
Douglas Medin, Scott Atran
}

\section{To cite this version:}

Douglas Medin, Scott Atran. The Native Mind: Biological Categorization and Reasoning in Development and Across Cultures. Psychological Review, 2004, 2004 (4). ijn_00000565

\section{HAL Id: ijn_00000565 \\ https://hal.science/ijn_00000565}

Submitted on 25 Jan 2005

HAL is a multi-disciplinary open access archive for the deposit and dissemination of scientific research documents, whether they are published or not. The documents may come from teaching and research institutions in France or abroad, or from public or private research centers.
L'archive ouverte pluridisciplinaire HAL, est destinée au dépôt et à la diffusion de documents scientifiques de niveau recherche, publiés ou non, émanant des établissements d'enseignement et de recherche français ou étrangers, des laboratoires publics ou privés. 
The Native Mind:

Biological Categorization and Reasoning

in Development and Across Cultures

\author{
Douglas L. Medin \\ Northwestern University, Evanston IL \\ (medin@northwestern.edu) \\ and \\ Scott Atran
}

Centre National de la Recherche Scientifique, Paris

The University of Michigan, Ann Arbor MI

(satran@umich.edu) 
Abstract. This paper describes a cross-cultural and developmental research project on naïve or folk biology, that is, the study of how people conceptualize nature. The combination of domain specificity and cross-cultural comparison brings a new perspective to theories of categorization and reasoning and undermines the tendency to focus on "standard populations." From the standpoint of mainstream cognitive psychology, we find that results gathered from standard populations in industrialized societies often fail to generalize to humanity at large. For example, similarity-driven typicality and diversity effects and basic level phenomena either are not found or pattern differently when we move beyond undergraduates. From the perspective of domainspecificity, standard populations may yield misleading results, because such populations represent examples of especially impoverished experience with respect to nature. Conceptions of humans as biological kinds vary with cultural milieu and input conditions. We also show certain phenomena that are robust across populations, consistent with notions of domain-specificity. 


\section{Introduction.}

To get along in the world, people need to be able to understand and predict the general properties and behaviors of physical objects and substances (physics), the more specific properties of plants and animals (biology), and the particular properties of their fellow human beings (psychology). This paper describes an ongoing program of research in the domain of naïve or folk biology, including aspects of its interfacing with folkpsychology. The topics range from simple categorization to complex inductive inferences. The contexts vary from the lowland rainforest of Guatemala to the most technologically-developed urban settings. The study populations extend from the standard undergraduate research pool to Itza' Maya elders in Guatemala who have no formal education, on the one hand, and to botany PhD's on the other; they also range from middle class children living near major US universities to Yukatek Maya children of rural Mexico.

In this paper we argue that the combination of cross-cultural research with conceptualizing biological cognition as a privileged, domain-specific competence provides a new perspective on a range of fundamental issues in cognition. This includes: 1 . a need to revise current models of categorization and reasoning, which have been developed on a narrow empirical base, culturally speaking, 2. an analysis of the relative contributions of universal versus culturally-specific processes to people's conceptions of biological kinds, and 3. A shift in appraisal of the role of so-called "standard" populations from constituting a norm to seeing them as reflecting the cognitive consequences of diminished contact with nature.

This paper can be read from two closely- related perspectives. From the point of view of mainstream cognitive psychology, we find that results gathered from "standard populations" more often than not fail to generalize to humanity at large. In the area of categorization, 
similarity-driven typicality effects and basic level phenomena either are not found or play out differently when we move beyond undergraduate participants. In research on category-based reasoning, we find again that undergraduates are the "odd group out," which has corresponding implications for models of induction. In developmental studies we again find both culture and experience affect the status of results that had been at least implicitly treated as universal.

Interwoven in our research program is the notion that domain-specific cognitive modules facilitate and structure cognition. We argue that this framework is useful but that, in the case of naïve biology, using standard populations may produce misleading results, because such populations represent examples of especially impoverished experience with respect to nature. Nonetheless, the very fact of limited input makes results with these populations of considerable interest - they show which aspects of biological cognition are especially resilient. The pattern of universal and culturally-variable results illuminates our understanding of biology as a domain.

With respect to methodology, our research constitutes a distinctive point of view with respect to cultural psychology. In this paper we provide a description of some of the conceptual issues that have provided a framework for our research. This framework serves as a guide to a number of methodological issues that inevitably arise in cultural research. In a companion paper we contrast our view of culture and cultural models with a number of competing conceptions and illustrate its efficacy in studies of cultural differences in mental models and environmental decision making (Atran and Medin, submitted).

\section{Biology as a Module of Mind and a Core Cognitive Domain}

At the level of theory, we attempt to describe the scope and limits of folkbiology as a functionally autonomous domain of human cognition by concentrating on cross-cultural regularities (including systematic differences) in structure and development. In this section, we 
outline our approach to domain-specific cognition in general, and introduce our conjectures about the structure of the folkbiology module.

We hypothesize a folkbiological system (FBS) of the human mind that discriminates and categorizes parts of the flux of human experience as "biological," and develops complex abilities to infer and interpret this structured, core cognitive domain. In a general sense, there is nothing different about FBS - in terms of innateness, evolution or universality - than the visual system (VS) or any other evolved cognitive system (cf. Chomsky, 2000). FBS is no more (or less) "autonomous" from the surrounding social environment, or from other mental systems, than VS is detachable from surrounding light and object patterning or from other physical systems (including linguistic and other cognitive systems of meaning, Marr, 1982). FBS does not exist, and cannot develop, in isolation, but only as subsystems of even more intricate and interdependent structures. Thus, claims about the biological "autonomy" or "modularity" of FBS refer only to a specifiable level of systemic functioning within a system hierarchy.

How FBS combines with local environmental conditions and cultural history to produce people's actions upon the environment is the subject of a companion paper (Atran \& Medin, submitted). There, we also outline a more general approach for the study of culture and cognition. In this paper, however, we restrict our focus to acquiring knowledge of folkbiology. How FBS interfaces with folkpsychological (Carey, 1995) and folkmechanical (Au \& Romo, 1999) systems is a subject of current controversy in developmental and cognitive psychology. We have little to say about the interface between folkbiology and folkmechanics. To be sure, there is a substantial body of information on perceptual triggering conditions for attributions of animacy (e.g., Heider \& Simmel, 1944; Premack, 1990; Bloom \& Veres, 1999; Csibra, et al, 1999); however, there is only sparse and scattered work on how groups of animals 
and plants are assigned causal properties (by perceptual analyzers or otherwise) that distinguish them (e.g., as group essences) from inert objects on the basis of perceptual cues and mechanical indicators of boundary and movement. In contrast, ever since Carey's (1985) pioneering studies, the relation between folkbiology and folkpsychology has come under intense experimental scrutiny (Keil, 1989; Gelman \& Wellman, 1991; Inagaki \& Hatano, 1993).

Our present knowledge of evolutionary mechanisms and history is generally too poor to generate causal explanations of cognition. Often, evolutionary accounts are mere consistency arguments - "just-so stories" - that lack evidentiary standards for ruling out indefinitely many contrary evolutionary scenarios (Atran, in press). There have been more constrained evolutionary accounts of higher-order cognitive functions specific enough to motivate competing and informative research (e.g., Pinker \& Bloom, 1990; Cosmides \& Tooby, 1992). So far, however, these accounts arguably do little more than retrodict findings generated independently of any evolutionary considerations (e.g., Hauser, Chomsky \& Fitch, 2002; Sperber, Cara \& Girotto, 1995). ${ }^{1}$ At the same time, we hope to illustrate how evolutionary argument can be useful - even if not necessary - to progress in the field. A factor motivating our experiments, and our interpretation of them, is evolutionary plausibility. We do not claim that evolutionary arguments have explanatory value, only heuristic value.

Humans and their ancestors undoubtedly depended for their survival on intimate interaction with plants and animals, which likely required anticipatory knowledge of at least some plant and animal species. This makes it likely (but not necessary) that adaptations for special dealings with plants and animals evolved, and, further, that they evolved in a manner somewhat independent of adaptations for dealings with other people. For example, identification and categorization is different for humans, on the one hand, and for animals and plants, on the 
other. There are cognitive mechanisms primarily dedicated to tracking humans as individuals, such as facial recognition (e.g., Carey \& Diamond, 1977; Diamond \& Carey, 1986), syntactic and semantic structures of pronomilization and proper naming (Balogh, et al., 1998; Arnold, et al., 2000) social game strategies (Axelrod, 1985; Nowak \& Sigmund, 1998), and so forth. For animals and plants, the default recognition strategies are focused at the collective, species level (individualization of pets involves anthropomorphic extensions of person-identification strategies). From an evolutionary vantage, it hardly would matter which member of a plant or animal species a person could eat or be eaten by, but it would matter greatly who in particular a person could mate, fight or cooperate with (Eldredge, 1986). As we will argue, one implication of this analysis for folkbiological cognition is that results focused at the level of individuals do not necessarily carry over to studies at the level of species, and vice versa.

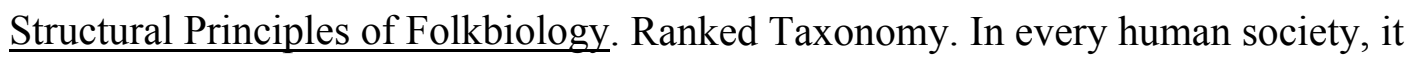
appears, people tend to think about plants and animals in the same special ways. These special ways of thinking, which can be described as "folkbiology," are basically different from the ways humans ordinarily think about other things in the world, such as stones, tools or even people:

From the most remote period in the history of the world organic beings have been found to resemble each other in descending degrees, so that they can be classed into groups under groups. This classification is not arbitrary like the grouping of stars in constellations. (Darwin, 1859:431).

The structure of these hierarchically-organized groups, such as white oak/oak/tree or mountain robin/robin/bird, is referred to as "folkbiological taxonomy." These nonoverlapping taxonomic structures can often be interpreted in terms of speciation (related species descended from a common ancestor by splitting off from a lineage). ${ }^{2}$ 
The human taxonomic system for organizing species appears to be found in all cultures (Berlin, Breedlove, and Raven, 1973, 1974; Atran, 1990). It entails the conceptual realization that, say, apple trees and robins belong to the same fundamental level of (folk)biological reality, and that this level of reality differs from the subordinate level that includes winesap apple trees and mountain robin as well as from the super-ordinate level that includes trees and birds. This taxonomic framework also supports indefinitely many systematic and graded inferences with respect to the distribution of known or unknown properties among species (Atran, 1998). Biological ranks are second-order classes of groups (e.g., species, family, kingdom) whose elements are first-order groups (e.g., lion, feline, animal). Folkbiological ranks vary little across cultures as a function of theories or belief systems (Malt, 1995). Ranks are intended to represent fundamentally different levels of reality, not convenience (Berlin, 1992).

Teleological Essences. There is also growing cross-cultural evidence of a commonsense assumption that each species has an underlying causal nature, or internal essence, which is uniquely responsible for the typical appearance, behavior and ecological preferences of the kind (Atran, Estin, Coley \& Medin, 1997; Atran, 1998; Atran et al, 2001; Gelman and Wellman, 1991, Gelman, 2003; Sousa, Atran \& Medin, 2002). We speculate that this notion of biological essence may be universal. People in diverse cultures consider it responsible for the organism's identity as a complex entity governed by dynamic internal processes that are lawful even when hidden. This essence maintains the organism's integrity from birth even as it causes the organism to grow, change form and transmit the same causal cycle across generations. Thus, a tadpole and frog are conceptualized as the same animal although they look and behave very differently, and live in different places. For these reasons, teleological essentialism, which applies uniquely to 
living kinds, is more specialized than mere sortal essentialism, which applies to all nominalized objects (e.g., desk, gold) and intrinsic qualities (e.g., red, liquid) (Rips, 1995; Atran, 1998)

Western philosophers, like Aristotle and Locke, attempted to translate this commonsense notion of essence into some sort of metaphysical reality, but evolutionary biologists reject the notion of essence as such (e.g. Mayr, 1982). Nevertheless, biologists have traditionally interpreted this conservation of identity under change as due to the fact that organisms have genotypes separate from phenotypes. Although science does not abide metaphysical essentialism, there is a wide variety of evidence supporting the notion of psychological essentialism (Ahn, et al, 2001); that is, even when people do not have specific ideas about essences they may nonetheless have a commitment to the idea that there is an underlying nature (i.e., they may have an "essence placeholder;" Medin and Ortony, 1989). This hidden, causal essence is presumably responsible for the emerging and manifest properties of the kind. The fact that biological science can overturn psychological essentialism in theory construction in no way implies that psychological essentialism can be dismissed from everyday thought, any more than physical science's rejection of constant intervals of space and time implies alterations in our ordinary use of absolute space and time (Atran, 1987).

The idea of an essence placeholder allows that people may come up with different mechanisms for conveying or modifying causal essence. Some mechanisms may be more plausible choices than others. For example, beating of the heart and circulation of blood give prima facie mechanical evidence for causal activity. In addition, loss of blood and stopping of the heart are often signs of loss of life. Thus, heart and blood may be privileged candidates for the locus of essence, as it has been throughout the history of European societies (Atran, 1990). Even contemporary Americans who undergo heart transplants show evidence of believing that at 
least some aspects of essence have been transmitted from the donor to the recipient (studies cited in Gelman 2003). In different cultural settings (e.g., milk as conveyer of essence through nursing), other plausible candidates may have priority (Stoler, 1995). Willingness to allow transformations of essential kindhood (e.g., through blood transfusions, organ transplants) may depend upon cultural context (Jeyifous 1992, Mahalingham 1998).

For the moment we will defer addressing the question of whether a hierarchical taxonomy and the presumption of essence are domain-specific (see Hirschfeld, 1995, and Atran, 1995 for one round of arguments). Different kinds of categories may conform more or less well to a hierarchy (many social categories do not) and people may, at least in a weak sense, essentialize all categories (see Rips, 1995). But a system of rank is not simply a hierarchy, and it is less clear that there is anything corresponding to a cross-culturally stable sense of teleological essences for nonbiological kinds (for an attempt to rank artifacts, see Brown, Kolar, Torrey, Troung-Quang \& Volkman, 1976; for opposing arguments, see Atran, 1987; for findings contrary to attributions of essences to artifacts, see Sloman \& Malt, in press). None of our central claims hinge on whether or not patterns of categorization and reasoning are confined solely to naïve biology.

Biology as a module of mind. Different cognitive scientists have offered alternative and sometimes conflicting notions of modules so we will take a few paragraphs to say what we mean by modules. We consider that there are roughly two classes of evolved cognitive modules: perceptual modules and conceptual modules. A perceptual module has automatic and exclusive access to a specific range of sensory inputs, its own proprietary database, and may not draw on information produced by other conceptual modules or processes. A perceptual module is usually associated with a constrained neural architecture, and fast processing that is not accessible to 
conscious awareness. Examples may be modules for facial recognition, color perception, identification of object boundaries, and morpho-syntax (Fodor, 1983).

A conceptual module works on a privileged, rather than strictly proprietary, database that is provided by other parts of the nervous system (e.g., sensory receptors or other modules), and which pertains to some specific cognitive domain (Atran, 1990:285). Examples include folkmechanics, folkbiology and folkpsychology. ${ }^{3}$ The argument for conceptual modules - as in the case of folkbiology - involves converging evidence from a number of venues: Functional design (Pinker, 1997; Atran, 1998), ethology (Cerella, 1979; Hernstein, 1984; Brown \& Boysen, 2000), universality (Berlin et al., 1974; Brown, 1984; Atran, 1990), precocity of acquisition (Stross, 1973; Dougherty, 1979; Hatano \& Inagaki, 1999), independence from perceptual experience (Gelman \& Wellman, 1991; Atran et al., 1997; Sousa et al., 2002), selective cerebral impairment (Sartori \& Job, 1988; Caramazza, 2002), resistance to inhibition (hyperactivity), and cultural transmission. None of these criteria may be necessary, but presence of all or some is compelling, if not conclusive. Here, we will only consider the latter two principles because they are rarely a part of discussions of modules (for a full discussion of principles, see Atran, 2001). ${ }^{4}$

Resistance to Inhibition and Hyperactivity. One characteristic of an evolved cognitive disposition is evident difficulty in inhibiting its operation (Hauser, 2000). Consider beliefs in essences. Such beliefs greatly help people explore the world by prodding them to look for regularities and to seek explanations of variation in terms of underlying patterns. This strategy may help bring order to ordinary circumstances, including those relevant to human survival. But in other circumstances, such as wanting to know what is correct or true for the cosmos at large, such intuitively ingrained concepts and beliefs may hinder more than help 
Because intuitive notions come to us so naturally they may be difficult to unlearn and transcend. Even students and philosophers of biology often find it difficult to abandon commonsense notions of species as classes, essences or natural kinds in favor of the concept of species as a logical individual - a genealogical branch whose endpoints are somewhat arbitrarily defined in the phyletic tree and whose status does not differ in principle from that of other smaller (variety) and larger (genus) branches (Ghiselin, 1981). Similarly, racism - the projection of essences onto social groups - seems to be a cognitively facile and culturally-universal tendency (Hirschfeld, 1996). Although science teaches that race is biologically incoherent, racial or ethnic essentialism is as notoriously difficult to suppress as it is easy to incite (Gil-White, 2001).

Cultural Transmission: Human cultures favor a rapid selection and stable distribution of those ideas that: a) readily help to solve relevant and recurrent environmental problems, b) are easily memorized and processed by the human brain, and c) facilitate the retention and understanding of ideas that are more variable (e.g., religion) or difficult to learn (e.g., science) but contingently useful or important. Folkbiological taxonomy aids humans in orienting themselves and surviving in the natural world. For example, in societies the world over, inherently fluid social groups acquire greater conceptual and practical stability when conceptually associated with folkbiological species; that is, as elements of totemic societies (Levi-Strauss, 1962). As noted earlier, its content tends to be fairly stable within cultures (high inter-informant agreement, substantial historical continuity) and structurally comparable across cultures (Berlin, et al., 1973). Over time and different cultural settings, taxonomic structure and content may become deeper or shallower (as with industrialized populations). Nevertheless, its organizational principles remain robust. Folkbiological taxonomy also continues to serve as a 
principled basis for transmission and acquisition of more variable and extended forms of cultural knowledge, such as certain forms of religious and scientific belief (Atran, 1998, 2002).

In sum, the sort of cultural information that is most susceptible to modular processing is the sort of information most readily acquired by children, most easily transmitted from individual to individual, most apt to survive within a culture over time (provided adequate input and cultural support), most likely to recur independently in different cultures and at different times. Critically, it is also the most disposed to cultural variation and elaboration. It makes cultural variation comprehensible.

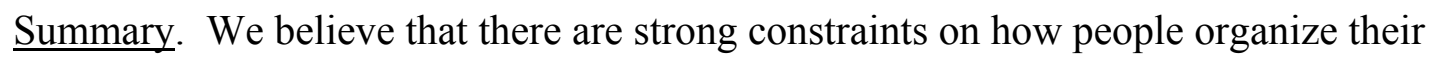
local knowledge of biological kinds. These evolutionary constraints form a "learning landscape" that shapes the way inferences are generalized from particular instances or experiences. It produces consensus even though specific inputs vary widely in richness and content. Thus, many different people, observing many different exemplars of dog under varying conditions of exposure to those exemplars, may nonetheless generate more or less the same concept of $\underline{\mathrm{dog}}$.

To say an evolved biological structure is "innate" is not to say that every important aspect of its phenotypic expression is "genetically determined." Biologically poised structures "canalize" development, but do not determine it - like mountains that channel scattered rain into the same mountain-valley river basin (Waddington, 1959). Cultural artifacts can - purposely or inadvertently - further channel developments in various directions, like dams or water-gates placed at different locations.

Our burden of proof is to show that the above analogy forms a meaningful pattern rather than a mish-mash of vague ideas and speculations. As a guideline and overview, we provide a summary of our central theoretical and empirical claims, along with our assessment of the 
corresponding state of evidence, in Table 1. We will return to this table in the General Discussion.

\section{INSERT TABLE 1 ABOUT HERE}

\section{Cross-Cultural Comparison}

Our claims concerning folkbiology rely heavily on comparative research, typically within- and across-cultures. One cannot begin to conduct this type of research without making a series of methodological and conceptual commitments. One reason that comparative research has not been popular is that it is not always clear how to do it successfully. When one compares two groups and finds clear differences interpretative problems quickly emerge. Which of the many ways in which the two groups differ are crucial? For example, López, Atran, Coley, Medin, and Smith, (1997) found that US undergraduates and Itza' Maya of Guatemala showed different patterns of responding on a category-based inductive reasoning task involving mammals. Although this undermines the universality of the particular reasoning phenomenon, the two groups differ in myriad ways (e.g. age, education, literacy, livelihood, language, cosmology and so on). Which of these differences matters? Practically speaking, it may be impossible to disentangle these various factors. Suppose we could control for age, education, literacy and the like in comparing Itza' Maya and undergraduates. How do we decide which variables represent "culture" and therefore should not be controlled, and which variables do not, and should be 
controlled. The Itza' Maya practice agro-forestry and also hunt and collect plants in the forest. Should these factors be controlled or are they part of Maya culture?

Now suppose that we control for every variable we can think of and still find differences. In this case, it seems that one is more or less forced to reify or essentialize culture. That is, the only explanation of the cultural difference involves appealing to some abstract notion of “culture." In short, it seems we may be caught between two equally undesirable possibilities: One is to end up with a notion of culture that solely has recourse to circular explanations of differences ("the Itza' are different because they are Itza'"). The other is to conclude that cultural comparisons just represent confounded experiments and that the notion of culture is not needed once proper experimental control is achieved.

Another problem associated with comparative research is the issue of sampling. If we want to know how the Itza' categorize and reason, we had better take a random sample of Itza', else our results may not generalize to the Itza' population as a whole. But the sample used by López, et al, 1997, was anything but random---it consisted of Itza' Maya elders who speak Itza’ Maya. That fact alone makes the sample unusual and unrepresentative because Itza' Maya is a dying language; the "typical” Itza' speaks mainly Spanish. How can one justify nonrandom sampling? In what follows, we describe our methodological strategy for cultural comparisons.

Triangulation as a research strategy. There is no theoretically-neutral way to define culture (in a companion paper we offer a theoretical framework and methodology for conceptualizing culture, Atran \& Medin, submitted). We have just suggested that the idea that culture is whatever is left when all potentially confounding variables are controlled is selfdefeating. Granted, it is useful to control for variables that are clearly irrelevant to culture. But 
one must bear in mind that decisions about what is irrelevant are necessarily theory-based and commit one to a particular notion of culture.

Because (cultural) groups cannot be found that represent orthogonal combinations of variables, it may be in principle impossible to disentangle the various sources of variation among groups. The general idea of triangulation is to use observations from a third group to get at least modest leverage for understanding initial group differences. The third group should resemble one group in some potentially important ways and the second group in other ways. If the third group performs like one of the groups and different from the other group, then the variables shared by the third group and the group it mimics become candidates for critical variables.

To illustrate this strategy, consider López et al, 1997. In that study, we compared Itza' Maya elders and University of Michigan undergraduates on categorization and reasoning involving local mammals (local to Petén, Guatemala and Michigan, USA, respectively.) We tell informants of a new disease that we know affects coyotes and wolves, and another new disease that affects coyotes and cows. Now we ask which disease is more likely to affect all mammals. University of Michigan undergraduates overwhelmingly say the disease that coyotes and cows get is more likely to affect all mammals. They justify their answers by appealing to the dissimilarity of the two premises, or diversity. That is, they say that if some disease affects such different mammals as coyotes and cows, it is likely to affect all mammals. This reasoning strategy seems straightforward and the Osherson, et al., 1990, model for category-based reasoning predicts that people will prefer more diverse premises in drawing inductions to a category. What is surprising is that the Itza' Maya do not show a diversity effect. In some cases they are reliably below chance in picking the more diverse premises on these kinds of tests. 
Why don't the Itza' use a diversity-based reasoning strategy? Obviously, there are any number of hypotheses one could conjure up. Perhaps the question wasn't asked quite the same way in Itza' Maya (back translation is no guarantee of equivalence), or perhaps formal education is a pre-requisite for this form of abstract thought, or perhaps the Itza' have a very different conceptualization of disease. It just isn't clear.

Here is where our triangulation strategy proved to be effective. In this case the third group was USA tree experts who were asked to reason about novel tree diseases. USA tree experts resemble Michigan undergraduates in many respects (language, formal education, etc.) and resemble Itza' with respect to having considerable domain knowledge. A typical diversity probe might be as follows: "White pine and weeping willows get one new disease and river birch and paper birch get another. Which is more likely to affect all trees?" Using these kinds of probes Proffitt, Medin, and Coley (2000) found that parks workers, like the Itza', showed reliably below chance diversity responding. Later on, we will describe what strategies Itza' and parks workers share. For now, we simply note that the triangulation strategy pinpoints domain knowledge as a key variable in diversity responding (though as we'll see, not the whole story).

At first glance, it might appear that the triangulation strategy is just a $2 \times 2$ design with one cell missing. But a 2 X 2 design presumes what the triangulation strategy is intended to discover, namely, which factors are crucial to group differences. The logic of triangulation implies compression of any number of possible 2 X 2 designs that together entail a host of possible explanations for group differences. Instead of $2^{\mathrm{N}}$ controlled designs, each of which allows inference to a single factor, a carefully chosen third group deliberately confounds a number of variables. By carefully choosing a third group, $\mathrm{C}$, that resembles the first group, $\mathrm{A}$, in a number of ways and the second group, B, in a number of other ways one can assess the relative 
importance of the set of culturally-confounded variables by which C differs from A versus those by which $\mathrm{C}$ differs from $\mathrm{B}$.

Non-Random Sampling. Cultures are not static but relentlessly develop, dissolve, merge and mutate. Nonetheless, it seems sensible to look for sharp contrasts by means of selecting subpopulations that have retained more traditional knowledge. These considerations lead one to employ sampling techniques most likely to reveal cultural differences rather than focusing on estimating population parameters. Consider again the López, et al studies with the Itza' Maya. Younger Itza' might have notions of biology that differ from those of Itza' elders, differences that reflect assimilation to "Western culture." Thus a random sample may tend to hide rather than reveal cultural differences. Instead of randomly selecting participants, López et al restricted their sample to Itza'-speaking Maya as the best representatives of Itza' culture. It's not that there was some pure Itza' culture in the past that nowadays is being degraded---cultural change is a constant. Itza' cultural life is a rich blend of ideas and habits stemming from different inputs, including a great deal of Spanish influence. A random sample is only appropriate when one wants to make claims about population parameters, something that we believe is rarely relevant in cultural comparisons.

A Final Methodological Point. The streets of unfortunate cross-cultural comparisons are strewn with studies that began with methodologies developed in the USA and then rigidly applied to other populations of interest. It is very important to be sensitive to the potential for cultural misunderstandings arising from task instructions and interpretation. This threat can be substantially reduced through careful pretesting informed by ethnographic, ethnohistorical, ethnobotanical and ethnolinguistic preparation. 
For example, broad cross-cultural agreement in biological categorization should not conceal the fact that different elicitation procedures may yield different patterns of taxonomic or ecological sorting. Thus, in pretests with Itza', we asked them to sort things most "similar" (b'ay) or "alike" (je-b'ix) to replicate as closely as possible instructions given to American subjects (e.g., Boster \& Johnson, 1989). Initial results were discouraging: consensus across participants was low, and informants seemed to justify sorts by often idiosyncratic and conflicting notions of use (e.g., horses and cows are more similar to one another than to tapirs because tapirs don't carry loads; tapirs and cows are more similar to one another than to horses because horses are not eaten at festivals). But ethnohistory indicates that the expression of a deeper taxonomic reasoning endures over time (Trager, 1939; Bartlett, 1940). Thus, 16th century Itza' taxonomically assimilated the horse (a perissodactyl) by identifying it as a kind of tapir (the only native perissodactyl) (Landa, 1985[1566]). Itza' still attach the same name to the horse (zimin) and tapir $\left(\underline{\operatorname{tzimin} \sim \mathrm{che}^{\prime}}=\right.$ forest $\left.\underline{\text { tzimin }}\right)$, although they are maximally distant by functional criteria: the former is terrestrial, domestic and inedible; the latter is aquatic, wild and edible. Interviews reveal that Itza' consider the tapir and horse to be "companions by nature" (et' ok, "go together"). This proved the key to asking Itza' to sort items that "go together by nature," which yielded taxonomies resembling those found in cultures the world over (López, et al, 1997). By contrast, there was no significant difference in the performance of American students asked to sort items that "go together by nature" or as being "most similar."

Similar sorts of analyses and pretesting accompanied preparation of all of our instructions. One advantage of tailoring instructions to a variety of nonstandard populations is that they can be further applied to other populations with greater ease and confidence than if they had been simply translated from instructions given to undergraduates or other groups affiliated 
with large research universities and urban environments in the USA. Moreover, we have found that the instructions so pre-tested usually can be successfully reapplied to standard populations.

Summary. We have spent considerable time in describing our framework for comparative research in folkbiology, in part because of its contrast with previous approaches to cultural comparison. The stage is now set to begin a systematic review of empirical results in relation to theories. In each study set, our findings contrast sharply with previous generalizations.

\section{Study Populations and Related Methodology.}

In the next several paragraphs we will describe the main study populations in our research. The reader less interested in the specific characteristics of the populations may wish to skip ahead to that section.

\section{Mesoamerica.}

Itza' Maya. A good deal of our work concerns native Itza' Maya in the municipality of San Jose in Guatemala's Department of El Petén. Men are primarily occupied with practicing agriculture and horticulture, hunting game and fish, and extracting timber and non-timber forest products for sale. Women mainly attend to household gardening and maintenance. The climate is semitropical, with quasi-rainforest predominating (tropical dry forest / subtropical humid forest).

Yukatek Maya. We have also worked with children and adults from Yukatek-speaking rural villages in southcentral Quintana Roo, Mexico. Yukatek were chosen because of their close linguistic and cultural connection with the Itza', and because there are thousands of Yukatekspeaking children but no more children who speak Itza' as a first language.

\section{North American Populations.}

It has also been helpful to collect data from a number of USA populations. When we began to study folkbiology with the standard undergraduate populations it soon became clear that 
the typical college student knows very little about plants and animals. Consequently we sought out a variety of other US populations. There is also evidence that urban and suburban children may have relatively impoverished experience with nature (compare Stross, 1973, on Maya children's knowledge and naming of plants with Dougherty, 1978, on Berkeley children) and, therefore, our developmental studiesalso involved several different groups.

Undergraduates. This group hardly needs description. They consist of students taking introduction to psychology at major research universities in the Midwest.

Biology “Experts." This category includes diverse groups with distinct kinds of expertise: Bird watchers, parks maintenance workers, landscape architects, and professional taxonomists. They typically had at least 20 years experience in their occupation or avocation.

Menominee. Adults. The Menominee ("Wild Rice People") are the oldest continuous residents of Wisconsin. There are 4-5000 Menominee living on tribal lands in and around three small communities. Over $60 \%$ of Menominee adults have at least a high school education and $15 \%$ have had some college. As in the past, the reservation is heavily forested. Hunting and fishing are important activities for most adult males and for many females.

Children. The Menominee children attended an elementary school on the Menominee reservation. Although they tend to know some Menominee words, especially those for clan animals, they are basically monolingual English speakers.

Rural Majority Culture. Adults. Adjacent to the Menominee reservation is Shawano County, which consists of farmland, small forests, and numerous lakes and rivers. Hunting, fishing, water recreation in the summer, and snow-mobiling in the winter are popular activities. Our adult participants came from in and around the community of Shawano. 
Children. The majority culture children attended an elementary school in Shawano. About $20 \%$ of the children live on farms. As in the case of the Menominee children, it is not uncommon for preschool children to be introduced to fishing.

Urban children. The urban children attended an elementary school in Boston, Massachusetts. The school is located in East Boston and serves a middle class community.

\section{Relation of Folkbiology to Folk Psychology}

In her influential 1985 book Susan Carey proposed that young children's understanding of living things is initially embedded in a folkpsychological, rather than folkbiological, explanatory framework and that human beings act as the prototype. Her data suggested that children did not develop an independent model of biology where humans were seen as one animal among many until they were 10-12 years old. In short, on this view, children have to undergo a fundamental conceptual change to achieve an autonomous biology.

A strong form of evidence for this theory comes from an inductive inference task where children are told that some novel property is true of one biological kind (e.g. "Humans have a little green thing inside them called an omentum."), then are asked whether that property is true of other biological kinds (e.g. "Do you think that dogs also have an omentum?"). Three major findings bolster the claim that children's conceptions of the biological world are anthropocentric. First, children more readily project properties from humans to other living kinds than they project properties from other living kinds to one another or to humans. The other two findings are consequences of this difference in induction potential. The second result concerns asymmetries in projection: inferences from human to mammals are stronger than from mammals to humans. Third, 4-year old children violate projections according to similarity: inferences from 
humans to bugs are stronger than from bee to bugs. Together, these findings suggest that humans are the preferred base for young children's inferences about the biological world.

Carey's claims have not gone unchallenged and her book has served to stimulate a large body of research on children's biology. The current consensus appears to be that even young children do have distinct biological theories (see Carey, 1999, Inagaki and Hatano, 2001 and Gelman, in press, for extensive reviews), though these theories may differ systematically from the science that they must learn in school. Nonetheless Carey's induction task continues to be of interest. There is work which suggests that the relative prominence of psychological versus biological construals of biological kinds is sensitive to contextual factors (Guntheil, Vera and Keil, 1998). Our work suggests that there is an important cultural and experiential dimension that merits attention. Specifically, our evidence suggests that the anthropocentrism observed by Carey in young children does not reflect a failure to distinguish biology from psychology. Instead, we believe that humans serve as prototype because human beings were the only biological entity that young urban children knew very much about.

Research on children's biology has been conducted almost exclusively with individuals from North American, urban, technologically-advanced populations. In the few studies that go beyond this sample (e.g., Inagaki and Hatano in Japan), the focus is still on urban, majorityculture children from technologically-advanced societies. Thus, it is not clear which aspects of children's naïve biology are likely universal and which depend critically on cultural conceptions and conditions of learning. Human-centered reasoning patterns might reflect lack of knowledge about nonhuman living things rather than a radically different construal of the biological world.

To evaluate the role of cultural milieu and conditions of learning in children's inductive reasoning we have studied four populations: urban Boston children, rural Wisconsin majority 
culture children, Menominee children, and Yukatek Maya children of varying ages (4 to 11) and adults (Ross, et al, 2003, Atran, et al, 2001). All testing in the USA was in English; Yukatek Maya was used for the Maya children and adults.

Detailed color drawings of objects were used to represent base and target categories. Four bases were used in Mexico: Human, Dog, Peccary and Bee. Targets were divided into two sets. Each set included a representative of the categories Human (man, woman), Mammal (deer, coatimundi), Bird (eagle, chachalaca), Reptile (boa, turtle), Invertebrate (worm, fly), tree (Kanan, Gumbo Limbo), Stuff (stone, mud), Artifact (bicycle, pencil) and Sun (in both sets). The USA populations were given Human, Wolf, Bee, Goldenrod, and Water as bases and a corresponding set of mammals, birds, reptiles, invertebrates, plants, stuff and artifacts as targets.

As in Carey's studies, children were shown a picture of one of the bases and taught a new property about it. Thus, the experimenter might show the dog picture, and say, "Now, there's this stuff called andro. Andro is found inside some things. One thing that has andro inside is dogs. Now, I'm going to show you some pictures of other things, and I want you to tell me if you think they have andro inside like dogs do." Participants were then shown each of the targets and asked: "Does it have andro inside it, like the [base]?" Properties were unfamiliarly internal substances of the form "has X inside." A different property was used for each base.

$\underline{\text { Results. }}$ The pattern of responding varied substantially across groups. The young urban USA children (5-6-year-olds) generalized in a broad, undifferentiated manner and the only clear trend was greater generalization from a human base to a human target than to other targets. Older urban children (9-10-year-olds) generalized in terms of biological affinity but showed a strong asymmetry in reasoning between humans and other animals. Although these data do not replicate 
Carey's precise findings, they agree in the outcome that young urban children did not generalize based on biological affinity.

The young, rural majority culture children revealed a different pattern; they showed the mature pattern of generalizing in terms of biological affinity. Interestingly, both they and older rural children showed asymmetries in reasoning between humans and animals and often justified a failure to extend a property from an animal to humans on the grounds that "people are not animals." This observation strongly suggest that the asymmetry does not derive from humans being conceptualized as the "prototypic" animal. Instead, seeing humans as animals may be something of a developmental achievement, as suggested by Johnson, Mervis, and Boster (1992; see also the sorting task in Carey, 1985). Finally, older rural children gave some evidence of reasoning in terms of ecological relations, as when they justified generalizing from bees to bears because a bee might sting a bear or a bear might acquire the property by eating the bee's honey.

Menominee children demonstrated yet a third pattern. First, even the youngest Menoninee often reasoned in terms of ecological relations. In addition, children of all ages generalized in terms of taxonomic relatedness and showed no reliable human-animal asymmetries. The Menominee origin myth has people coming from the bear, and even the youngest children are familiar with the animal-based clan system. In short, there is cultural support for a symmetrical relation between humans and other animals.

Findings from studies of inductive projection among Yukatek Maya also do not replicate Carey's results with urban American children (compare Figures 1 and 2) and are not consistent with the claim that folkbiology is anthropocentric until late childhood. Here we present data from younger children (4-5 year-olds). First, for Yukatek Maya, like Menominee children: 1.

Projections from humans are no stronger than projections from other living kinds. 2 . There is no 
overall human-animal asymmetry. 3. Young children do not violate their own perceptions of similarity out of preference for humans as an inductive base.

\section{INSERT FIGURES 1 and 2 ABOUT HERE}

There are, however, asymmetry effects for the youngest Yukatek girls with respect to a wild versus domestic animal base (Human -> mammal > Peccary $->$ human) and for the youngest children overall in regard to inferences involving invertebrates. The fact that such asymmetries are not generalized across the youngest age group suggests that they are the result of familiarity rather anthropocentric bias as such. Younger girls are less familiar with wild animals than younger boys, and younger children on the whole are less familiar with invertebrates than they are with humans or mammals. Less familiarity with wild animals and invertebrates may favor them less as sources of induction. The fact that dogs are a better base for induction than are peccaries is consistent with this observation. Apparently, the more properties a child knows about some kinds, the more likely they are to generalize some new property to other living kinds.

Young children (especially the girls) generalized in a fairly undifferentiated way from humans (Figure 3). It is not clear how to interpret this pattern of results. One possibility is that these children lack a clear grasp of how humans fit into the tree of life (the girls show the same pattern with the peccary, an animal with which they are unfamiliar). Another possibility is that humans, being the primary focus of ecological interactions, provide a plausible inductive base for thematic relationships that may have little correlation with taxonomic distance.

\section{INSERT FIGURE 3 ABOUT HERE}


On the whole, Yukatek Maya children look much like Menominee children but with some intriguing gender differentiation. These gender differences may reflect the strong sexual division of activity that is institutionalized early in the first year of life. In the jeetz meek' ceremony, Maya girls are introduced by the women to household utensils, whereas Maya boys are introduced by the men to agricultural and hunting tools. Later in life, Maya women will spend their time almost wholly in the vicinity of the house and house garden, in close interaction with domestic animals. By contrast, Maya men spend days, weeks and even months in the forest away from home. For Maya females, dogs are household animals, whereas men value dogs as hunting animals. Maya boys also venture out into the forest with their fathers at an early age, and so become familiar with wild animals, such as the peccary, before girls do. These findings suggest that induction patterns may be influenced by relative familiarity with animals and by the culturally-specific character of the functional and ecological relationships between humans and other natural categories of elements.

Overall, it appears that lack of intimate contact with plants and animals is responsible for the anthropocentric bias observed with urban American children. Consistent with this view, Inagaki (1990) presents evidence that experience influences children's biological reasoning. She found that kindergarteners actively involved in raising goldfish were more likely than their counterparts who did not raise goldfish to reason about a novel aquatic animal (a frog) by analogy to goldfish rather than by analogy to humans.

The observation that young (Native American) children often engage in ecological reasoning seriously complicates the interpretation of the induction task. Consequently, the induction task may have limited utility, unless it is supplemented by additional converging 
evidence. What is clear is that anthropocentrism and human-animal asymmetries in reasoning are the exception, not the rule.

Childhood Conceptions of Species Essences. Given the framework outlined at the beginning of this paper we would expect that essentialism would be among the most robust features in children's (and adult's) reasoning. Young of a species have the potential to develop certain adult characteristics before those characteristics appear. The origins of these characteristics can be explained in two broadly different ways: nature and nurture. Some characteristics seem likely to develop from birth because they are essential to the species to which the individual belongs, such as a squirrel's ability to jump from tree to tree and hide acorns. Other characteristics are determined by the environment in which the individual is reared, such as a squirrel's fear or lack of fear of human beings.

Gelman and Wellman (1991) argue that young children predict category-typical characteristics of individual animals based on the innate potential of the animal (i.e. the species of its birth parent) rather than the environment in which it was raised (i.e. the species of its adoptive parent). Using an adoption study, they showed that four-year-old children judge that a baby cow raised by pigs will have the category-typical characteristics of cows (moos, straight tail) rather than pigs (oinks, curly tail). They interpret the results as showing that preschoolers believe that the innate potential or essence of species determines how an individual will develop, even in contrary environments. ${ }^{5}$

This study has been criticized as inconclusive with regard to children's assumptions about innate potential for two reasons. First, because the experimenters told the child that the baby and mother were of the same species, the study does not address the question of how the children identify to which species the baby belongs in the first place (Johnson \& Solomon, 
1997). Given this explicit verbal identification, one cannot rule out that the children's performance owes to an essentialist bias that is a general property of language; that is, children might expect that the animal would continue to have the properties of the labeled species, even in the absence of reasoning about the mechanism involved (Gelman \& Hirschfeld, 1999) ${ }^{6}$.

Second, the study explored only known facts about species and their associated properties. It did not examine whether or not children use the concept of biological parentage as an inferential framework for interpreting and explaining hitherto unknown facts. It may be that a child has learned from experience, and as a matter of fact, that a calf is a cow because it was born to a cow. Still, the child may not know that having certain kinds of parents causes a cow to be a cow (Carey, 1995).

We have been studying several culturally-distinct populations to test the extent to which children's assumptions about innate species potential govern projection of both known and unknown properties. In one study (for details see Atran et al, 2001), Yukatek Maya children and adults were presented with a forced-choice task involving an adoption scenario. They were asked whether an adult animal adopted at birth would resemble its adoptive parent (e.g., cow) or birth parent (e.g., pig) on four different individual traits: known behaviors (e.g. moo / oink), known physical features (e.g. straight / curly tail), unknown behaviors (e.g. looks for chachalacas / looks for pigeons), and unknown physical features (e.g. heart gets flatter / rounder when it is sleeping). Known traits were context-free, category-typical features that the children readily associate with species, whereas unknown traits were chosen to minimize any possibility of factual or pre-learned associations of traits with categories. Each unknown trait within a set was attributed to the birth parent for half the participants and to the adoptive parent for the other half. This assured that projection patterns of the unknown traits were not based on prior associations. 
Stories were accompanied by sketches of each parent. Sketches were designed to unambiguously represent a particular species of animal with minimum detail. In addition, sketches of known physical features (e.g. a sketch of a curly or straight tail), unknown physical features (e.g. flat vs. round heart) and relevant aspects of unknown behavioral contexts (e.g., closed vs. open eyes when afraid, stops in front of mahogany vs. cedar trees) were shown to participants. These sketches in no way indicated the species to which the traits belonged.

The story was followed by two comprehension questions: 1."Who gave birth to the baby? and 2."Who did the baby grow up with?". Children then were presented with the experimental probes. For example they might be told: "The cow mooed and the pig oinked. When the baby is all grown up will it moo like a cow or oink like a pig?" The probes were followed by a bias control in which the participant was asked: "When the baby was growing up did it eat with animals that looked like X or animals that looked like Y?" (Notice that this last probe involves an inference and is not simply a memory check).

Overall, results showed systematic and robust preference for attributions from the birth parent. This preference was observed for all Yukatek age groups and for known and unknown behavior and physical properties. The trend was somewhat stronger in older children and adults and slightly stronger for known than unknown properties. The low mean on the bias control probe for all groups indicates that the method of the current experiment did not bias participant responses toward the birth parent. 
In work with USA urban and rural majority culture children, with Menominee children, and with three groups of urban children in Brasilia (Brazil), we also find that young children show a strong pattern of inferencing in terms of birth parents (e.g. Sousa, et al, 2002). The developmental trajectory of this pattern varies across populations, sometimes weakening in older children and other times strengthening (Table 2). In addition, judgments about whether biological manipulations such as, for example, a blood transfusion (where the baby's blood is replaced by blood from the adoptive parent) changes kindhood also varies across culture and development. Overall the data are consistent with a universal initial assumption of an underlying essence for biological kinds that may be somewhat modified by the cultural landscape. ${ }^{7}$ These findings, together with Gelman and Wellman's (1991) earlier results, raise the possibility such an essentialist bias in children may be universal.

There are two types of objections to our claims that we will briefly consider. One is simply an empirical issue: is this pattern of results truly universal? Bloch, Solomon and Carey (2001) report that 7-13 year-old Zafimaniry children from a remote village in Madagascar reasoning about an adoption scenario show a bias toward adoptive parents, an apparent counterexample to our claims. We have four reservations about this study. First, the features attributed to adoptive and birth parents were not counter-balanced and tended to be much more negative for the adoptive parent. Informants may have the belief that negative properties are more powerful and dominate positive qualities (e.g. as in the historical "one-drop rule" in southern states; see also Stoler, 1995). Second, the children in the Bloch et al study were a ways older than they were in our studies. Thus, Hirschfeld (1966) shows that, for racial categories, fifth and sixth graders show strong social effects not apparent in second graders. We find greatest agreement (and a 
birth bias) in the youngest children in our various populations. The ideal test case for our hypothesis is a culture where the adults are not essentialists about ethnicity (see Astuti, 1995, but also Gil-White, 2001 for cautions concerning claims about adult conceptions). Here we would still expect that young children would be essentialists (certainly for animals and perhaps for humans as well) even if adults were not (though adults may be essentialists about animals other than humans).Third, there was a striking difference in social class between the birth and adoption families, and the vitiating possibility that asymmetrical class distinctions could asymmetrically weigh upon conceptions of inheritance and identity.

Finally, the Zafiminary concept is different in that it usually involves relatives and is not permanent. Hence one would have more confidence in a study involving animals other than humans. Furthermore, as we indicated earlier, on evolutionary grounds, there is reason to expect that reasoning about animal and plant species may be different from reasoning about people. Indeed, in follow-up studies with the Vezo of Madagascar, Astuti and Carey (Carey, 2003) found a reliable birth bias for the youngest children they tested (6 years old) when animals rather than humans were used in the adoption scenario.

Another objection to our data is that we may be guilty of over-interpreting the results in the sense that projection on the basis of species membership should not be equated with projection on the basis of some essence (see Rips, 2001 for an amplification of this criticism). An alternative view is that children are employing ideas about causal relations but that they may have no notion of "essence" whatsoever (Strevens, 2000). Although this distinction may be subtle, we have discussed it at length elsewhere (see the Ahn, et al, 2001, commentary) and will confine ourselves to a few remarks in the context of summarizing this section. 
Summary. The combination of developmental and cross-cultural studies confirms universal aspects of children's folkbiological cognition, suggests that biology is a conceptual domain distinct from psychology, and indicates that anthropocentrism in young children is the exception, not the rule. These same sorts of comparative studies reveal components of biological cognition that varies systematically as a function of cultural milieu and input conditions (intimacy of contact with nature). The fact that young Native American children often reason in terms of ecological relations poses a challenge for interpreting patterns of projection on the induction task. On the other hand, the prominence of ecological reasoning points to a component of children's biology that has scarcely been studied, in part because this pattern has scarcely evident in developmental studies with "standard" populations. Finally, we note that the attribution of essences to species-like groupings has implications for the organization and structure of taxonomies and the basic level.

Our claim is that from a quite early age children have intuitions that the mechanisms underlying essential causes are biological. The essential causal relations are those involving, for example, birth, biological relatedness and internal structure. Just how detailed these notions are and how they are modified by experience and cultural milieu awaits further comparative study.

\section{The Essence of the Basic Level.}

Ever since the pioneering work of Berlin and his colleagues, ethnobiological evidence has been accumulating that human societies everywhere have similar folkbiological structures (Berlin, Breedlove \& Raven, 1974, Hunn, 1977, Hays 1983, Brown, 1984, Atran, 1990, Berlin, 1992). Striking cross-cultural similarities suggest a small number of organizing principles that universally define systems of folkbiological classification. Most folkbiological systems have between three and 
six ranks. Taxa of the same rank are mutually exclusive and tend to display similar linguistic, biological and psychological characteristics.

The most general rank is the folk kingdom. Examples are PLANT and ANIMAL. Such taxa are not always explicitly named, and represent the most fundamental divisions of the biological world. These divisions correspond to the notion of "ontological category" in philosophy (Donnellan, 1971) and psychology (Keil, 1979). From an early age, it appears, humans cannot help but conceive of any object they see in the world as either being or not being an animal (Inagaki \& Hatano, 1993) and there is evidence for an early distinction between plants and nonliving things (Hatano \& Inagaki, 1999). Conceiving of an object as a plant or animal seems to carry with it certain presumptions that are not applied to objects thought of as belonging to other ontological categories, like the category of substance or the category of artifact (Keil, 1989).

The next rank down is that of life form. Most life-form taxa are named by lexically unanalyzable names (primary lexemes), and have further named subdivisions. Examples are TREE and BIRD. Biologically, members of a single life form are diverse. Psychologically, members of a life form share a small number of perceptual diagnostics, such as stem habit, skin covering and so forth (Brown, 1984). Life-form taxa may represent general adaptations to broad sets of ecological conditions, such as the competition of single-stem plants for sunlight giving rise to trees (Hunn, 1982, Atran, 1985). Classification according to life form may occur relatively early in childhood. For example, familiar kinds of quadruped (e.g., dog and horse) are classed apart from sea versus air animals (Mandler, Bauer \& McDonough, 1991).

The core of any folk taxonomy is the generic-species level (also called folk generic, Berlin, 1992; see Atran, 1990 on the historical development of biological categories). Like life-form taxa, generic-species taxa are usually named by primary lexemes, like OAK and ROBIN. Sometimes 
generic species are labeled as binomial compounds, such as HUMMINGBIRD. On other occasions, they may be optionally labeled as binomial composites, such as OAK TREE. In both cases the binomial makes apparent the hierarchical relation between the generic species and the life form.

Generic species comprise the overwhelming majority of taxa in any folkbiological system. They often correspond to scientific genera or species, at least for the most phenomenally salient organisms, such as larger vertebrates and flowering plants (Atran, 1987, Berlin, 1992). Generic species are also typically the categories most easily recognized, most commonly named and perhaps most easily learned by children (Stross, 1973). Ethnobiologists who otherwise differ in their views of folktaxonomy tend to agree that one level best captures discontinuities in nature and provides the fundamental constituents in all systems of folkbiological categorization, reasoning and use (Bulmer, 1974, Hunn, 1982, Ellen, 1993). On evolutionary grounds one would expect that innate potential is vested at the generic species level: for the most part, generic species are genetically, geographically and reproductively isolated (Mayr, 1982, calls these "nondimensional species"). Hence, we would expect presumptions of essence to be at the generic-species level, where innate potential is.

Given these observations, results of psychological studies of privilege or basicness are striking and puzzling. In a justly celebrated set of experiments, Rosch and her colleagues set out to test the validity of the notion of a psychologically privileged taxonomic level (Rosch et al., 1976). Using a broad array of converging measures they found support for the view that there is a "basic level" in category hierarchies of "naturally occurring objects," such as "taxonomies" of artifacts as well as living kinds (cf. Brown, et al., 1976). For artifact and living kind hierarchies, the basic level is the most abstract level where: (1) many common features are listed for categories, (2) consistent motor programs are employed for the interaction with or manipulation of category exemplars, and (3) category members have similar enough shapes so that it is possible to recognize an average 
shape for objects of the category. The basic level is also preferred in adult naming, first learned by children and the level at which entities can be categorized most rapidly.

Thus, work by Berlin and by Rosch both indicate a privileged level in category hierarchies. Moreover, both claim that this privileged take on naturally occurring objects is directly tied to objective discontinuities in the real world. But the basic level that Rosch et al., (1976) had hypothesized for living kinds, which Rosch initially presumed would accord with Berlin's folkgeneric rank, did not prove to be privileged. For example, instead of MAPLE and TROUT, Rosch et al. found that TREE and FISH operated as basic-level categories for American college students. Thus, Rosch's basic level for living kinds generally corresponds to Berlin's life-form level, which is super-ordinate to the generic-species level.

How can we reconcile the discrepancy between Berlin's observations and Rosch's data concerning privileged levels? In one attempt to do so, Dougherty (1978) argued that the basic level is a variable phenomenon that shifts as a function of general cultural significance and individual familiarity and expertise (cf. Tanaka \& Taylor, 1991; Johnson and Mervis, 1997). Thus, most folk in industrial societies often have little distinctive familiarity with, knowledge of, and use for various species of trees, fish, birds and so forth. As familiarity with the biological world decreases, there is a gradual attrition of folkbiological knowledge up the hierarchy, with the basic level devolving from the generic-species to the life-form levels. A related (but alternative) view of the Berlin/Rosch discrepancy is that it is sensitive to how privilege is measured. Specifically, some measures of privilege may be driven more by experience than others (see also Barsalou, 1991).

In brief, discrepancies in findings for different populations suggest that the basic level is knowledge-dependent. There is evidence that biological experts have a more specific basic level than novices, but this describes results from a novice perspective. We offer a reframing. 
"Experts" and people from small-scale societies have "normal" basic-level categories, corresponding to a default inference / recognition strategy whose recognition component degenerates with lack of exposure, but whose inference component remains intact.

There is reason to prefer our framing. Our studies focus on inductive inference. One might expect novice, expert, and small-scale groups to privilege their respective basic levels for induction (e.g., tree for USA students, oak for experts and Maya); however, our studies indicate that both industrialized and small-scale populations prefer the same folktaxonomic rank for induction. (Atran, et al.,1997; Coley, et al.,1997).

Inductive inference allows people to extend knowledge beyond their immediate experience and beyond the information they are given, and is a crucial part of category formation and use (Rips, 1975, Smith \& Medin, 1981). Use of inductive inference as a tool is also motivated by the experiments in the last section suggesting that generic species are characterized by a presumption of essence that directs the search for underlying causal principles and theories (cf. Medin,1989). Inductive inference must be a mainstay of any such search for underlying causal principles.

Examining inferences from a given rank to the adjacent higher-order rank, we found a sharp decline in strength of inferences to taxa ranked higher than generic species, whereas strength of inferences to taxa ranked lower than generic species were nearly equal and similarly strong (Figure 4). While all ranks may not be relevant to all cultures - or not relevant in the same ways - some categorization processes may be relatively immune to cultural differences. Thus, people from traditional versus high technology cultures may differ in terms of the level at which names readily come to mind, or the level at which taxa are most easily imaged, or the level at which their biological knowledge is most complete. Nevertheless, they may presume that the same rank is privileged for biological reasoning, namely, the rank of generic species. 


\section{INSERT FIGURE 4 ABOUT HERE}

Based on extensive fieldwork, we chose a set of Itza' folkbiological categories of the kingdom (K), life-form (L), generic-species (G), folk-specific (S), and folk-varietal (V) ranks. We selected three plant life forms $\left(\underline{\mathrm{che}}=\right.$ tree, $\underline{\mathrm{ak}^{\prime}}=$ vine, $\underline{\mathrm{pok} \sim \mathrm{che}^{\prime}}=$ herb/bush $)$ and three

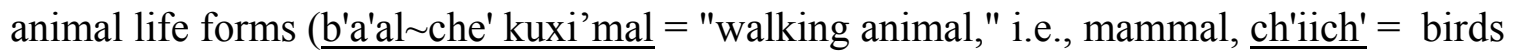
including bats, käy $=$ fish). Three generic-species taxa were chosen from each life form; each generic species had a subordinate folkspecific, and each folkspecific had a salient varietal. The properties chosen for animals were diseases related to the "heart" (pusik'al), "blood" (k'ik'el), and

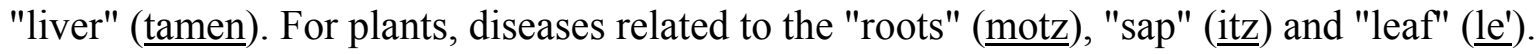
Properties were chosen according to Itza' beliefs about the essential, underlying aspects of life's functioning. Properties used for inferences had the form, "is susceptible to a disease of the $<$ root $>$ called $<\mathrm{X}>$." For each question, "X" was replaced with a phonologically appropriate nonsense name (e.g. "eta") to minimize the task's repetitiveness. All participants responded to a list of questions in which they were told that all members of a category had a property (the premise) and were asked whether "all," "few," or "no" members of a higher-level category (the conclusion category) also possessed that property.

In one set of experiments, the premise category was at one of four levels: life-form (e.g., $\mathrm{L}=$ tree, mammal), generic-species $(\mathrm{G}=$ oak, dog $)$, folk-specific $(\mathrm{S}=$ white oak, poodle $)$, or varietal ( $\mathrm{V}=$ swamp white oak, toy poodle). The conclusion category was drawn from a higher-level category. Thus, there were ten possible combinations of premise and conclusion 
category levels: L->K, G->K, G->L, S->K, S->L, S->G, V->K, V->L, V->G, and V->S. For example, a folk-specific-to-life form (S->L) question might be: "If all white oaks are susceptible to the called eta, are all other trees susceptible?" If a participant answered "no," then the followup question would be: "Are some or a few other trees susceptible, or no trees at all?"

We totaled the proportion of "all" responses for each kind of question (e.g., the proportion of times respondents agreed that if white oaks had a property, all oaks would have it). We counted a response of "all" as 3, "some or few" as 2, and "none" as 1. A higher score reflected more confidence in the strength of an inference. Examining inferences from a given rank to the adjacent higher-order rank (i.e., V->S, S->G, G->L, L->K), we found a sharp decline in strength of inferences to taxa ranked higher than generic species, whereas $\mathrm{V}->\mathrm{S}$ and $\mathrm{S}->\mathrm{G}$ inferences were nearly equal and similarly strong. For "all" responses, the overall Itza' and Michigan patterns were very similar. For example, given a premise of folk-specific (white oak, poodle) and a conclusion category of generic-species rank (oak, dog), most respondents indicated that all members of the generic species would possess a property that the folk specific has. A comparable number of respondents also indicated that a property possessed by a folk varietal (swamp white oak, toy poodle) would as likely be found with the generic species (oak, dog) as with the folk specific (white oak, poodle). In contrast, few respondents believed that properties found in a folk varietal, folk specific or generic species would be found among all members of the superordinate life-form (tree, mammal) or folk-kingdom (plant, animal) categories, or that properties found in a life form would generalize to the folk kingdom.

Nevertheless, in the combined response scores ("all" + "few") there was evidence of increased inductive strength for higher-order taxa among Americans versus Itza'. In other words, both Americans and Itza' showed the largest break between inferences to generic species versus 
life forms; however, only American students also showed a consistent pattern of rating inferences to life-form taxa higher than to taxa at the level of the folk kingdom: G->K vs. G->L, S->K vs. S->L, and V->K vs. V->L. For the Americans, the preferred level of perceptual identification (life form) appeared to have a secondary effect on inference, whereas for Itza' the life-form level seems to carry no inductive privilege. Although the students cannot perceptually identify most bird or tree species, they can readily form (and draw) an abstract image of BIRD or TREE. Itza' only consent to draw particular kinds of birds or trees.

These results indicate that both the inexperienced Americans and the Itza' elders prefer taxa of the generic-species rank in making biological inferences. In related work with USA botanical experts Schwartz and Medin (2000) also found clear evidence of privilege at the generic-species level. If inferential potential were a simple function of perceptual similarity, then American nonexperts should prefer life forms for induction (as with Rosch et al., 1976). The findings suggest that root categorization and reasoning processes in folkbiology owe to conceptual assumptions (about the causal locus of biologically essential attributes at the genericspecies level) and not exclusively to general, similarity-based (e.g., perceptual) heuristics. To be sure, language may signal expectation that little or poorly known generic species are more biologically informative than better known life forms for Americans (e.g., via common use of binomials, such as oak / red oak). But our experiments still show reliable results in the absence

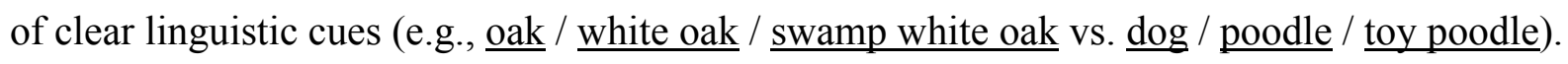
Undergraduates' lack of close contact with biological kinds may be precisely what allows us to tease apart the contributions of perceptual processes and abstract expectations to the privileged level in induction. There is now considerable evidence for perceptual learning (e.g. for recent work see Goldstone, 1994, Schyns, Goldstone, and Thibaut, 1998) in general as well as 
evidence that the basic level on perceptual tasks becomes more specific with expertise (e.g. Tanaka and Taylor, 1991, Johnson and Mervis, 1997). Expertise is almost always a relative term and one equally could cast these results into a different frame: so-called "expert' performance on perceptual tests could be the default stage of normal development and undergraduate performance on perceptual tests (favoring the more abstract life-form level) could be the result of a failure to undergo "normal" perceptual development with respect to biological kinds. If this were true, then we would expect Itza' to perform like experts on perceptual tests, and only for cases of impoverished input would we expect a discrepancy between abstract expectations and perceptual processes. Arguably, there is an evolutionary design to a cognitive division of labor between domain-general perceptual heuristics and (domain-specific) learning and inference mechanisms, the one enabling flexible adaptation to variable conditions of experience, and the other invariably steering us to those enduring aspects of biological reality that are both causallyrecurrent and relevant to the emergence of human life and cognition.

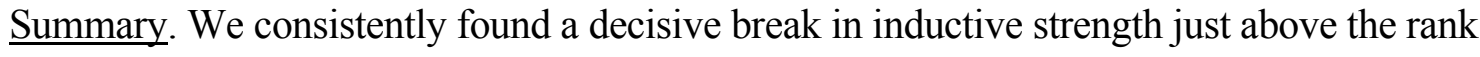
of generic species. Nevertheless, we also found secondary evidence that supports the downgrading of American folkbiological knowledge versus the upgrading of Maya knowledge, relative to the generic-species level. Specifically, we find Americans have more faith in inductions to superordinate life-form taxa than the Itza', and Itza' differentiate among subordinate taxa more than students. This observation, coupled with some suggestive data on the decreasing salience of biological kinds in western societies, raises further issues concerning the relativity of expertise.

\section{Devolution and Expertise.}

So far we have found it natural to treat undergraduates as the reference population and to categorize groups that know more than they do as "experts." Of course, by this standard, practically 
everyone with more contact with nature would be considered to be expert. Our alternative perspective is suggested when one takes the knowledge of the typical member of a nonindustrialized society as the standard. With this reference point, undergraduate knowledge would be considered much below average or "devolved."

A recent survey we conducted at Northwestern University offers some index of what undergraduates know about one domain of biology, namely trees (Coley, et al, 1999). We provided students with the names of 80 trees and asked students to circle the trees they had ever heard of before, regardless of whether they knew anything about them. More than 90 percent said that they had heard of birch, cedar, hickory, maple, pine and spruce. But fewer than half indicated any familiarity with alder, buckeye, hackberry, hawthorn, honey locust, linden, sweetgum, and tulip tree, all of which are common to the campus area (and in the case of the buckeye, is accompanied by the fact that the Ohio State Buckeyes are a fellow Big Ten School!). Although it would take time travel to firmly establish that Northwestern students know less than their counterparts of the $19^{\text {th }}$ century, there is indirect evidence that favors the devolution hypothesis.

Wolff, Medin, and Pankratz, (1999) examined a large sample of written material from the $16^{\text {th }}$ through the $20^{\text {th }}$ centuries contained in the online Oxford English Dictionary. Of interest was the relative frequency and specificity of the use of tree terms. We found a precipitous decline in the use of tree terms after, but not before the $19^{\text {th }}$ century (Figure 5). The number of sources mentioning trees declined by $45 \%$ and the number of quotes fell $40 \%$. Furthermore, the specificity of quotes declined between the $19^{\text {th }}$ and $20^{\text {th }}$ centuries. While the use of the life-form term, tree, only fell $26 \%$, the use of generic-species terms (e.g. oak, maple, pine) fell by $50 \%$. More detailed analyses showed that these declines were present regardless of whether the tree term was or was not the topic of the 
sentence. Finally, we found similar declines for other life-form terms, such as bird or grass, but only increases for non-biological super-ordinates, such as furniture and clothes.

\section{INSERT FIGURE 5 ABOUT HERE}

This evidence of diminished cultural support for biological kinds is consistent with our suggestion that undergraduates and urban, middle-class children are anything but a "standard" population when it comes to the domain of biology. In the previous section, we found that the standard population's (in this case, children) patterns of inductive projection across life forms, kingdoms and ontological domains (humans, animals, plants, artifacts) depends upon familiarity with the categories in question and perhaps cultural construals of the role of humans in nature, and do not readily generalize to other populations and cultural settings. In this section, we found that inductive projections within the domains of animal and plants show evidence of universal patterns of reasoning that were not previously apparent in standard populations (in this case, college students), and which seem relatively independent from cultural familiarity. In the next two sections, we will see further evidence that undergraduates are nonstandard with respect to folkbiological thought. We first examine typicality effects and then turn to the use of categories in reasoning.

\section{Typicality.}

Next to the notion of a basic level, perhaps the most important notion in the psychology of categorization is that of typicality effects. The idea is that some instances of a category may be better examples of a category than others. For example, a common intuition is that robins are better examples of bird than are chickens. Furthermore, the consensus has been that the basis of typicality effects is similarity relationships---robins are better birds because they are more similar 
to other birds than are chickens (see Smith, Shoben and Rips, 1974; Rosch and Mervis, 1975 for empirical and theoretical treatments of typicality). Once again, however, these observations rest on a narrow empirical base with respect to study populations.

Work on typicality judgments among Itza' shows that inductively useful notions of typicality may be driven more by considerations of idealness than central tendency (Atran, 1999). In each case for which we have direct Itza' ratings, the 'truest' or 'most representative' living kind categories are large, perceptually striking, culturally important, and ecologically prominent. For example, the three most highly rated mammals are the jaguar (also called 'The Lord of the Forest'), the mountain lion (the jaguar's principal rival) and the tapir (also called 'The Beast of All Seven Edible Kinds of Flesh'). The three most highly related snakes are the large and deadly fer-de-lance (Bothrops asper, also called 'The True Snake') and its companions, the large and venomous tropical rattlesnake (다미 us durissus) and the smaller but deadly coral (Micrurus sp.). The three most representative birds are all large, morphologically striking and highly edible Galliformes (wild fowl): ocellated turkey, crested guan, and great curassow.

One might wonder if somehow the instructions were different or whether typicality has a different meaning in the Itza' language. Further observations undermine this possibility. Lynch, Coley and Medin (2000) found that USA tree experts based their typicality judgments on ideals (e.g. height, absence of undesirable characteristics) and that central tendency was uncorrelated with judgments. Lynch et al. used instructions that followed verbatim those by Rosch and Mervis (1975) in their original studies showing central-tendency based typicality effects. ${ }^{8}$ The best predictor of undergraduate typicality ratings was word frequency. In other studies with birders (bird watchers) and fishing experts (majority culture and Menominee fishermen in Wisconsin) we also find that typicality is organized in terms of ideals and that central tendency is 
uncorrelated with judgments (Bailenson, et al, 2002; Medin, et al, 2002). The exact ideals vary somewhat with cultural group. For example, Menominee fishermen rate the culturally-important sturgeon as a better example of fish than do majority culture fishermen. Many Menominee think of the sturgeon as sacred and the tribe continues to have a sturgeon ceremony each spring. In earlier centuries the sturgeon was one of the first species to migrate upriver to spawn in the spring and was a major source of food.

No doubt similarity structures and similarity-based typicality are important determinants in natural categorization. Our findings suggest that for American undergraduates these may be dominant factors. But for our relative experts (US experts and Itza'), who have substantial knowledge, goals and activities about the items they classify and reason with, information other than that derived from perceptual clustering and similarity judgment is relevant to understanding natural biodiversity. Behavior and ecology, for example, appear to be crucial to the deeper and broader understanding of nature that scientists and birdwatchers seek.

In summary, we consistently find that among people knowledgeable about a domain, typicality judgments are based on ideals. Only undergraduates appear to rely on central tendency or word frequency. Of course, one might play down the significance of these findings by suggesting that they only hold for direct judgments of typicality. As we shall see in the next section, however, these effects also extend to how categories are used in reasoning.

\section{Use of Categories in Reasoning.}

Categorization tasks are of independent theoretical interest and self-contained, but they are also designed to provide the inferential framework for category-based reasoning. In this section we focus on models for use of categories in inductive reasoning in general, and biological inference in particular. The empirical phenomena of interest are typicality and diversity effects in 
reasoning. We briefly mentioned diversity effects in illustrating our triangulation strategy and now we return to them. To set the stage for our discussion, we briefly review one of the most influential models of induction, the similarity-coverage model (SCM) of Osherson, et al, 1990.

An important function of taxonomic classification is enabling generalizations between categories. Osherson et al. (1990) identified a set of phenomena that characterize category-based inferences in undergraduates, and formalized a model that predicts the strength of those inferences. Sloman (1993) has presented an alternative model, but for our purposes it makes the same predictions. Both models rely on the notion of similarity and similarity relations as a guide to induction. Rather than talk about inductive "inferences," Osherson et al. discuss inductive "arguments," in which facts used to generate the inference play the role of premises, and the inference itself plays the role of conclusion. Thus, inferring that all birds have ulnar arteries from the fact that Jays and Flamingos do, amounts to the argument: Jays have ulnar arteries, and Flamingos have ulnar arteries, therefore all birds have ulnar arteries. This argument is strong to the extent that belief in the premises leads to belief in the conclusion. For all SCM phenomena, the properties (e.g., have ulnar arteries) are said to be "blank." They are designed such that they do not favor one category over another at the same rank or level. For example, "has ulnar arteries" should be a priori equally likely to be true of Jays and Flamingos.

The SCM predicts that the strength of an argument from a premise to a conclusion will vary with the similarity of the premise category to the conclusion category. For example, an inference from cows to horses should be stronger than an inference from squirrels to horses because cows are more similar to horses than squirrels are. The SCM also predicts that typical members of a category will have greater inductive strength than atypical examples for the conclusions about the entire category. For example, an inference going from bears to all 
mammals should be stronger than an inference going from mice to all mammals because bears are more representative of the category than are mice. In the terms of the SCM, bear provides better "coverage" of the category than does mice because bears have greater average similarity to other category members than do mice.

Diversity also relies on the notion of coverage. Consider the following argument: "Cows and Horses get one disease, Cows and Squirrels get another disease, which disease is more likely to affect all mammals? López et al, 1997 found that, for arguments like these, undergraduates strongly preferred the argument having the more diverse premises (in this case, Cows and Squirrels, rather than Cows and Horses). From the perspective of the SCM the argument with the more diverse premises is stronger because it provides better coverage. Cows and Horses each likely have greater average similarity to members of the mammal category but this coverage is redundant--- the mammals to which cows are highly similar are the same ones to which horses are very similar. On the other hand, the mammals to which squirrels are similar are different from the ones to which cows are similar. The SCM relies on a measure of maximal average similarity and thus is sensitive to the presence of redundancy. Hence, the SCM predicts that diverse arguments will have greater inductive strength.

In order to develop predictions associated with the SCM, López et al, employed a sorting task where participants were asked to sort local mammals into to groups, to "put the animals that go together by nature into as many groups as you want. Subsequent sorting into sub- and superordinate categories created a hierarchical taxonomy for each participant, which were then combined to create a group taxonomic hierarchy. The rationale for eliciting such taxonomic hierarchies was to be able to indirectly, but "automatically," compute measures of similarity, 
typicality and category coverage from a single cognitive structure, without having to directly elicit separate measures (e.g., through independent ratings).

To justify combining individual sorts into an aggregate cultural taxonomy, López et al, first applied the cultural consensus model to the informant by informant agreement matrix for both the Itza' and undergraduate sample. Both groups showed a strong consensus. With these results in hand, distance in the consensual group taxonomy provides a key measure of similarity that was then used to study category-based inferencing.

Similarity predicts that the stronger inference should be the one where the premise is closest to the conclusion, with "closeness" measured as the number of nodes in the taxonomic tree (produced by cluster analyses) that one has to go through to reach the conclusion category from the premise category. Like Similarity, the metric for Typicality is also given by the taxonomy itself, as the lowest average tree distance. Thus, the typicality of a taxonomic item (e.g., a generic species) is the average taxonomic distance of that item to all other items in the inclusive category (e.g., life form). Finally, diversity is based on the average lowest tree distance between either of the premise categories and the members of the conclusion category.

López, et al. (1997) used the similarity-coverage model to investigate inductive reasoning about mammals among U.S. college students and Itza' Maya speakers. Although we found reliable similarity and typicality effects in both groups, ${ }^{110}$ the groups differed markedly in the extent of their use of diversity. As we noted earlier, U.S. undergraduates demonstrated powerful diversity effects whereas the Itza' were reliably below chance in the selection of arguments with more diverse premises both for mammals and palm.

Although the source of this striking finding was not obvious (see Atran 1998, Coley et al., 1999 for more discussion of possible explanations), two candidates are cultural influence and 
relative expertise. Perhaps diversity is a novice strategy used in situations where more specific knowledge is not available. Alternatively, perhaps it is a result of the emphasis on taxonomic classification in modern Western society. Our work among U.S. tree experts suggests that neither answer alone will explain the finding. Proffitt et al, 2000 found that groups of U.S. tree experts differ in their use of diversity-based reasoning: taxonomists and landscapers show reliable diversity-based reasoning (albeit nowhere as high as López et al.'s undergraduates), whereas maintenance workers show below chance diversity responding much like the Itza'. This suggests that neither relative expertise nor cultural influence alone determines whether diversity is seen as a viable inductive heuristic.

Why do many experts and Itza' not show diversity? Consider, first, the Itza'. Itza' justifications revealed that diseases did not function as blank predicates for the Diversity items but instead serve as triggers for ecologically-based inductions. In many cases, ecological considerations led participants to conclude that the argument with more diverse premises was actually the weaker. For example, one Itza' favored the argument RAT, POCKET MOUSE / MAMMAL over TAPIR, SQUIRREL / MAMMAL. She argued that tapirs and squirrels are less likely to pass on the disease because they require an ecological agent (a bat biting them) to get the disease in the first place, whereas rats and pocket mice are close enough "companions" that they do not need an ecological agent (a bat biting them) to get the disease. Ecological considerations also led to diversity-based inductions in a few cases. Thus, another Itza' reasoned, to the contrary, that rats and pocket mice live only where there is corn, sleep above ground, and do not travel in parts of the forest where other animals may catch their disease.

USA tree experts also frequently used content-based reasoning involving disease mechanisms and ecological diversity, which often led them to choose the less diverse premises 
(Proffitt, et al, 2000). Interestingly, the tree experts did not show typicality effects. Their justifications for typicality probes often appealed to "family size," where family refers not to scientific families but to generic species. This echoes our findings of privilege at the genericspecies level noted earlier. To further test the generality of these findings on typicality and diversity, we tested Itza' on yet other kinds and properties (e.g. "has little things inside"), and we also tested other USA expert groups. Let's look at one of these lines of research in further detail.

Triangulating with Birds. Bailenson, et al, (2002) studied three populations on categorizing and reasoning about birds: Itza' Maya of Guatemala, USA bird experts (bird watchers), USA novices recruited through ads placed on campus. The stimulus materials were pictures of Chicago-area USA birds and pictures of lowland Guatemala birds. The idea was to see if the experts responded differently to local versus exotic species. Itza' can be thought of as novices with respect to USA birds, but they have extensive experience with birds that they may bring to bear with novel bird species. Each set consisted of full-color illustrations of 104 bird species laminated onto index cards. The structure of the scientific taxonomy representing the US bird set was designed to correspond maximally with that representing the Tikal bird set. One notable difference was in the number of passerines (songbirds) in the two sets. Although passerines are the numerically dominant group both in Chicagoland and Mayaland, they are somewhat more prevalent in Chicagoland.

All participants were told that we were interested in how they organized their knowledge about birds. First, we showed them all 104 bird cards one at a time and asked them to name them "as specifically as possible." Next, all 104 cards were placed in front of the participant, who was asked to "put together the birds that go together by nature into as many different groups as you'd like." The experimenters asked the informant to explain their basis for each category. We then 
followed the same procedure used by López et al to create higher and lower level partitionings. The result was a hierarchical taxonomy of birds for each participant.

Correspondence to Scientific Taxonomy. In order to compare performance from each group to science, we used the scientific taxonomy to derive a pair-wise bird-by-bird folktaxonomic distance matrix by calculating the distance between all possible pairs of birds in the taxonomy. We used classical evolutionary taxonomy because it represents a reasonable compromise between similarity-based "phenetic," or numerical, taxonomy and theory-based cladistic, or phylogenetic, taxonomy (see López et al, 1997, for further discussion). We then compared the average matrix from each group to the science matrix. The mean correlations for each of the groups on the US birds were $.38, .60$, and .45 for novices, USA experts, and Itza' experts, respectively. Note that Itza' sorts agreed more with science than did novice sorts. The mean correlations for each of the groups on the Guatemalan birds were $.34, .70$, and .61 for novices, USA experts, and Itza', respectively. Again, Itza' sorts corresponded more closely with science than did novice sorts.

Novice correlations with science are reliable but quite low, in no case accounting for more than $16 \%$ of the variance. We take this as evidence that the structure of nature is not nearly so transparent as previous researchers have suggested (e.g., Boster, Berlin \& O’Neill, 1986), or at least that the structure of nature is not transparent in pictures of birds. It may be that our novices have had so little by way of meaningful interactions with birds that they have failed to learn which aspects, features, or dimensions are most relevant to organizing and classifying birds (see our earlier comments on perceptual learning).

There is some support for this interpretation. Johnson and Mervis (1997) tested bird experts, fish experts and novices on a triads task where participants were asked to pick out the 
two animals that were "most like the same kinds of thing." Some triads pitted overall morphological similarity against taxonomic membership. Not only were birds experts more likely to make the taxonomic choice for birds, and fish experts to make the taxonomic choice for fish; these two types of expert were also substantially more likely than novices to pick the taxonomic choice for the domain where they lacked expertise. These findings support the idea that some combination of perceptual learning and what they referred to as "intuitive theories" (e.g. understandings of the functional significance for the animal of different features) leads experts to organize biological kinds in a manner closer to scientific taxonomy.

Our results are consistent with this general interpretation in that the bird watchers and Itza' were using information not reflected in the novice sorts. In short, expertise appears to involve more than a passive reception of real world structure - it includes learning to attend to the features and relationships that are most informative, which does not necessary correspond with overall similarity (cf. Boster \& D’Andrade, 1989).

Category-based induction. We used the data from the sorting study to develop typicality and diversity probes to see how participants use bird categories and salient examples of birds in reasoning. Based on previous work we decided against using identical properties for the Itza' and US induction probes. Half of the probes involved disease and this was constant across groups. For the other half we used "enzyme" for USA subjects and "little things inside" for Maya subjects. We piloted both terms with both groups and found that USA adult participants were confused by "little things inside" but not "enzyme," "protein" or "disease X", whereas Maya subjects were confused by "enzyme" and "protein" but not by "little things inside" or "disease X." As in the sorting study we used probes involving both USA birds and birds of Tikal. 
For both kinds of probes we presented two pairs of birds and then asked about the property in question (disease, enzyme, or little things inside). For example, for the typicality trials, we displayed both birds in each pair and said:

"Let's assume that we discovered two new diseases. All we know about these diseases is that Disease A is found in these types of birds and Disease B is found in these. Which disease do you think is more likely to be found in all birds? “ For the diversity trials, we placed one pair of birds on the left-hand side and one pair of birds on the right hand side, and asked the same question.

Typicality Results. There were no differences as a function of property so we collapsed across this variable. Only the undergraduates (novices) showed any indication of a typicality effect. A look at the justifications for choices confirms this pattern. The most striking difference is that novices use typicality as a reason for the choice more than half of the time, while experts and Itza' never mention typicality. Both Itza' and US experts tended to use range or other ecological factors as justifications.

The passerine effect. We also analyzed the responses to the probes not simply in terms of typicality but also in terms of whether one of the birds in a pair was or was not a passerine. The US experts and novices chose the passerine over the nonpasserine (66\% and $86 \%$, respectively) more than the Itza' (40\%). In short, the Itza' experts tended to avoid passerines in their choices while the USA participants tended to choose them. As we will see, this difference probably derives from the salient role of non-passerines in Itza' Maya folkbiology.

Diversity. Again there were no differences as a function of property so we collapsed across this variable. Across conditions, US experts chose the more diverse pair on $58 \%$ of the trials, the novices also $58 \%$, and the Itza' $45 \%$. None of these percentages differed reliably from 
each other or from chance $(50 \%)$. The diversity pattern for the experts was largely driven by two experts. In justifications, novices tended to use either typicality or diversity as a justification and, at least initially, found typicality to be more compelling. Interestingly, they appeared to show something of a "learning effect" in that diversity justifications increased from $17 \%$ to $43 \%$ from the first to the second half of probes. It was as if once they hit upon this strategy, they thought it was a good one and tended to continue using it. Two experts gave almost exclusively diversity justifications; however, the other USA experts and Itza' predominantly responded in terms of ecological/causal relations. (Experts and Itza' showed no changes in patterns of justifications between the first and second half of probes).

The passerine effect again. The US populations tended to choose probe pairs involving passerines, whereas Itza' tended to avoid them. This passerine effect suggests that the idealness of the birds may be driving our results more than coverage. As we noted earlier for the Itza', passerines are not considered "true birds" to the same extent as other birds in the environment. Even though "passerine" was rarely cited as a justification, USA subjects tended to pick small songbirds as generalizing to the population of all birds while the Itza' preferred larger, more perceptually striking birds. Note, however, that for the Itza' and the experts the basis for responding is not idealness per se and their justifications did not directly appeal to either idealness or typicality. Given the prominent role of the larger game birds in the behavioral ecology of Mayaland, and the more interactive goals of Itza' in monitoring their ecology, the information provided by non-passerines would be more relevant to environmental understanding and management than information provided by songbirds. Itza' appear to monitor those species in their ecosystem (e.g., game birds as opposed to passerines) that provide the most relevant information about the interaction of human needs with the needs of the forest. Similarly, the 
most common justification by the USA experts on diversity probes was geographical range. Only the novice appealed to typicality per se on diversity probes. For the novices, whose interest in and interaction with the behavioral ecology is of a much reduced and altogether different order, correlated perceptual information may be more relevant by default.

Summary of Bird Studies. Our triangulation strategy again proved to be useful. For a number of important phenomena US experts and Itza' clustered together and contrasted with US novices. The expert groups sorted in closer correspondence with scientific taxonomy than did novices. This difference is particularly striking for Itza' on US birds because they were unfamiliar with Western science, scientific taxonomy, and the birds employed. US novices had prior exposure to the birds and to Western science but their sorts corresponded less well with scientific taxonomy than those of the Itza'. The data suggest that expertise confers benefits in abstracting important relationships in nature and, as a consequence, may lead to greater correspondence with scientific taxonomy. In that regard our results are well-anticipated by the findings mentioned earlier by Johnson and Mervis (1997) who showed that bird and fish experts were better able than novices to apprehend relational features tied to function and ecology.

The category-based induction findings also reinforce the view that the novices are the "odd group out." Novices relied very heavily on familiarity or typicality as the basis of their choices on both the typicality and diversity trials. Neither the Itza' nor the US experts ever gave typicality as a justification for either type of probe. Instead, they used knowledge about birds that the novices apparently did not possess. For example, both the Itza' and US experts frequently mentioned the geographical range of birds, an explanation that the novices rarely produced. This is a striking qualitative difference. 
Summary. We found patterns of expertise in natural categorization and reasoning that selectively transcend cultural boundaries: Itza' speakers and USA experts employ causal and ecological reasoning more than do USA novices, and the Maya and USA experts are better at discriminating one another's natural environment than the novices are at discriminating their own. One implication is that rich interaction with the environment and relative expertise is the evolutionarily-determined default condition for the operation of folkbiology. This has serious implications given the fact that US undergraduates comprise the one subject-pool in the literature that is consistently and overwhelmingly relied on for making psychological generalizations - not only with respect to folkbiology but also virtually every aspect of human cognition. In further followup work with Menominee and majority culture fishing experts in rural Wisconsin, we find that ecological/causal reasoning dominates and that neither typicality nor diversity effects are observed in either group.

An outstanding issue concerns the more general role that "standard" or "default" patterns of reasoning play in cognition and everyday life. What knowledge conditions are required to enable someone to "override" reliance on similarity-based typicality and diversity? Would experts "fall back" on central tendency and coverage if denied access to a rich knowledge base (e.g., in a novel domain)? The answer to these and other related questions await further studies.

\section{General Discussion, Implications, and Conclusions.}

Implications for Theories of Categorization and Reasoning.

Categorization. Two of the most robust and significant findings in the psychology of concepts are basic level phenomena and typicality effects. Our work suggests important modifications in each of these.

Basic level and essentialism. A serious conceptual problem is that both ethnobiology and 
cognitive psychology have argued for one, especially salient level of categorization but have disagreed about which specific level is privileged in biological taxonomies. The studies of Rosch et al, (1976), using measures of knowledge, naming preferences and perceptual tests found converging evidence for the life-form level as the most relevant. Ethnobiology favors the generic-species rank as privileged.

Our studies provide a way of reconciling this divergence. We think biological essentialism may be universal and plausibly linked to an evolutionarily-adaptive appreciation of generic species. For contemporary peoples in small-scale societies who continue to live intimately with nature, the level of generic species is the most relevant, as it likely was also for our hominid ancestors. When we used an induction task where performance can be based on either or both knowledge and expectation, we found convergence across cultures and expertise on the generic-species level as privileged for biological inference. The fact that biological experts also privilege the generic-species level on perceptual tests suggests that the divergence in question has little to do with how psychologists versus ethnobiologists measure the basic level. Rather, the apparent salience of the life-form level for undergraduates on feature listing and perceptual tests appears to be a peculiarity of the devolved state of undergraduate biological knowledge in particular, and that of industrialized populations in general (for a German example, see Zubin and Köpcke, 1986).

Why should the generic-species level be privileged for biological inference in the face of uncertainty? Because that is where the action was and, often still is, in human dealings with biological kinds. It would also be sensible for the perceptual system to be tuned to this same level of biological reality, and we suspect that this is the default condition for human beings who depend directly on nature for survival (i.e., without the intermediary of supermarkets and shops). 
Some perceptual learning may be necessary to achieve this consonance (e.g. Goldstone, 1998; Schyns and Rodet, 1997; Johnson and Mervis, 1997), experience that undergraduates may lack. More generally, people may have a perceptual-familiarity heuristic that allows them to rapidly and economically navigate their everyday world. This heuristic may be importantly influenced by cultural support (Wolff, et al, 1999). There is increasing evidence from studies with infants that words act as invitations to form basic level concepts (Waxman and Markow, 1995; Waxman, 1999), which in our society tend to focus on the life-form level (except for familiar pets and domestic animals; hence, bird, fish and $d o g$ are basic).

Typicality. The standard assumption has been that goodness of example, or typicality, is driven by similarity relations. A good example of a category is one that looks like its fellow category members and unlike members of contrasting categories (e.g., Rosch and Mervis, 1975; Smith, et al, 1974; Smith and Medin, 1981). As we noted, the SCM assumes that goodness of example effects extend to category-based induction.

Once again, however, results based on the standard undergraduate population proved to be atypical in the case of biological kinds. First, when the stimuli being judged are names of trees, undergraduates even fail to show similarity-based typicality. Instead, word frequency or familiarity is the best predictor (Lynch, et al, 2000). Apparently, undergraduates know too little about trees to even have a basis for computing similarities. More to the point, populations with domain familiarity, whether professional taxonomists or Itza' farmers, consistently organize categories in terms of ideals, such as the taxonomist's American elm or the Maya's wild turkey.

We believe that people who have serious commerce in a domain rarely approach it in a content-neutral manner, passively recording the regularities associated with the category. We saw that the Itza', for example, bias their observations of biological kinds toward those that are 
most perceptually- and ecologically-salient (e.g. large game birds, predators, and poisonous snakes). Parks workers worry about susceptibility to disease and other maintenance problems with local trees, and their typicality ratings reflect this concern. Majority culture fishermen attend to game fish and Menominee fishermen expand that focus to include sacred, culturallyimportant fish. In brief, the ways people deal with the world affect the ways they cognize it.

Category-based Inference. Much the same story can be told for typicality effects in reasoning, where responses to probes may be better predicted from knowledge of ideals than from computed central tendency. It is important to emphasize that the use of ideals in reasoning is indirect, rather than direct. That is, idealness per se plays no role in the rationale for responses. Instead, it is the implicit organization of knowledge organized around goals that both creates category ideals and drives category-based inference. For example, the Itza' Maya find passerines less relevant than gamebirds and raptors for understanding the forest (the forest being the primary focus of their understanding of the biological world). Consequently, they have much more knowledge about the large birds, knowledge that is recruited on reasoning tasks.

Although previous induction models have implicitly assumed that diversity-based responding is universal, it clearly is not. When we probed Itza', bird watchers, tree experts and fishermen in areas where they had knowledge we hardly ever observed diversity responses (and sometimes found below chance diversity). Obviously, observations such as these require a reformulation of inference theories (for a possible alternative based on "relevance theory," see Medin et al., in press).

Itza' noncompliance with diversity-based reasoning apparently results neither from a failure to understand the principle of diversity nor from any problems of "computational load." As with the most evident divergences between American and Itza' performance on similarity and 
typicality tasks, divergence from diversity apparently results from real-world concerns. In the absence of a theory - or at least the presumption of a theory - of causal unity underlying disparate species, there is no compelling reason to consider a property discovered in two distant species as biologically-intrinsic or essential to both (see also Proffitt et al, 2000). This does not mean that Itza' do not understand a diversity principle. In fact, in a series of tasks designed to assess riskdiversification strategies (e.g., sampling productivity from one forest plot or several) Itza' consistently showed an appreciation of the diversity principle in these other settings (López, et al., 1997). This suggests that although diversity may be a universal reasoning heuristic, it is not a universally-relevant aspect of folkbiological taxonomy, as we also found in US populations having more direct interest in the natural world.

Domain Specificity, Cultural Variation and Modularity. We have provided evidence for structural and functional autonomy of folkbiology in human cognition. First, our cross-cultural experiments on children's inductions from human to animals and vice versa indicated that humans are not the prototype that organizes the domain of animals. Second, young children from diverse cultures, who were tested on inheritance and adoption tasks, showed evidence for understanding the concept of innate potential of species. Third, our inductions experiments with regard to the basic level indicated that folkbiological taxonomies are universally anchored upon the generic-species level, where inductive potential is greatest. Fourth, our category-based induction experiments showed that people from diverse societies build topologically-similar biological taxonomies that guide inferences about the distribution of biological and ecological properties. Just how the taxonomies are used may vary across groups. For undergraduates, the taxonomy is a stand-in for ideas about the likely distribution of biologically-related properties 
(e.g. diseases). For the Itza' (and other knowledgeable groups) the taxonomy constrains the likely operational range of ecological agents and causes.

These universal tendencies are most salient outside the center of industrialized societies but nonetheless discernable everywhere. Our observations provide a cautionary tale: at least in the case of folkbiology, standard populations may be nonstandard and vice versa. Trying to understand the structure of folkbiology by focusing exclusively on relatively unknowledgeable college students may be akin to an attempt to understand the structure of language by concentrating on feral children. That is to say, we may be able to understand a great deal (e.g. about which aspects of biological cognition are least dependent on input conditions and direct experience) but only if we recognize this population a being atypical in commerce with nature.

Conclusion. We have outlined a framework where cultural and ecological inputs combine with innate propensities to determine biological cognition. Although we have not specified the mechanisms underlying this innate potential and their development with experience, we have provided a functional analysis and a set of candidate universal principles. Against the backdrop of such principles, we see patterned variation as a function of ecological and social contexts.

We are all born with native minds, though some develop in a manner better attuned to their natural surroundings than others. The full expression of the folkbiology module requires environmental triggering conditions and cultural support that may be lacking for certain groups in industrialized societies, including the usual subjects in most cognitive and developmental psychology experiments. From a theoretical perspective, the chief interest in studying these groups may not be to establish a baseline for generalizations about folkbiological knowledge, but to explore the cognitive consequences of limited input. 
Acknowledgements. This research was supported by grants from NSF (SBR 931978, SBR 9422587, SBR 9707761 SBR 9983260), NSF/EPA (SES-9981762), NIH (MH55079), the Russell Sage Foundation (87-99-02), and CNRS(contract no. 92 C 0758, MRT). This work is the summary of a combined effort by a number of long-term research collaborators: Norbert Ross, Elizabeth Lynch, Edilberto Ucan Ek', Valentina Vapnarsky, John Coley and Ximena Lois. Other important contributors and collaborators include: Jeremy Bailenson, Michael Baran, Serge Blok, Russell Burnett, Doug Cox, Paul Estin, Brett Hayes, Lawrence Hirschfeld, Alejandro López, Brad Love, Bobbi Low, Richard Nisbett, Connie Pankratz, Elizabeth Proffitt, Hillarie Schwartz, Michael Shum, Brian Smith, Edward Smith, Paolo Sousa, Gert Storms, Christopher Timura, Sandra Waxman, and Phil Wolff. Lance Rips, Susan Gelman, Lawrence Hirschfeld and Dan Sperber provided constructive comments on earlier draft of this manuscript. We are deeply grateful to our research partners and participants in Guatemala, Mexico, Brazil, Wisconsin, Illinois and Michigan, and especially to the Maya and Menominee communities that took us in. 


\section{References}

Ahn, W.-K., Kalish, C., Gelman, S., Medin, D., Luhmann, C., Atran, S., Coley, J. \& Shafto, P. (2001) Why essences are essential in the psychology of concepts. Cognition 82:59-69.

Arnold, J., Eisenband, J. Brown-Schmidt, S. \& Trueswell, J. (2000) The rapid use of gender information: Evidence of the time course of pronoun resolution from eyetracking. Cognition 76:B13-B26.

Astuti, R. (1995). "The Vezo are not a kind of people": Identity, difference, and "ethnicity" among a fishing people of western Madagascar. American Ethnologist, 22(3), 464-482.

Atran, S. (1985) The nature of folk-botanical life forms. American Anthropologist 87: 298-315.

Atran, S. (1987) Ordinary constraints on the semantics of living kinds. Mind and Language 2:27-63.

Atran, S. (1990) Cognitive foundations of natural history. Cambridge, UK: Cambridge University Press.

Atran, S. (1995). Classifying nature across cultures. In E. Smith \& D. Osherson (Eds.), An invitation to cognitive science, Vol. 3, Thinking. Cambridge, MA: MIT Press.

Atran, S. (1998) Folkbiology and the anthropology of science: Cognitive universals and cultural particulars. Behavioral and Brain Sciences 21:547-609.

Atran, S. (1999) Itzaj Maya folk-biological taxonomy. In D. Medin \& S. Atran (Eds.), Folk biology. Cambridge MA: MIT Press.

Atran, S. (2001) The case for modularity: Sin or Salvation? Evolution and Cognition 7:46-55.

Atran, S. (in press) Modest adaptationism. Behavioral and Brain Sciences 25. 
Atran S, Estin P, Coley J. \& Medin D. (1997). Generic Species and Basic Levels: Essence and Appearance in Folk Biology. Journal of Ethnobiology 17:22-45.

Atran. S. \& Medin, D. (submitted). The cultural mind: Ecological decision making and cultural modeling within and across populations. Psychological Review.

Atran, S., Medin, D., Lynch, E., Vapnarsky, V., Ucan Ek', E. \& Sousa, P. (2001) Folkbiology doesn't come from folkpsychology: Evidence from Yukatek Maya in cross-cultural perspective. Journal of Cognition and Culture 1:3-42.

Atran, S. \& Sperber, D. (1991) Learning without teaching: Its place in culture. In L. TolchinskyLandsmann (Ed.), Culture, schooling and psychological development. Norwood NJ: Ablex.

Axelrod, R. (1985). The evolution of cooperation. New York: Basic.

Bailenson, J., Shum, M., Atran, S., Medin, D. \& Coley, J. (2002). A Bird's Eye View: Biological Categorization and Reasoning Within and Across Cultures. Cognition 84:1-53.

Balogh, J., Swinney, D. \& Tigue, Z. (1998) Real-time processing of pronounswith contrastive stress. Poster presented at the 11th Annual CUNY Conference on Human Sentence Processing.

Barsalou, L. (1991). Deriving categories to achieve goals. In G.H. Bower (Ed.), The Psychology of learning and motivation: Advances in research and theory, Vol. 27. San Diego, CA: Academic Press.

Bartlett, H. (1940) History of the generic concept in botany. Bulletin of the Torrey Botanical Club 47:319-362.

Berlin, B. (1992) Ethnobiological classification. Princeton: Princeton University. 
Berlin, B., Breedlove, D., \& Raven, P. (1973) General principles of classification and nomenclature in folk biology. American Anthropologist 74:214-242.

Berlin, B., Breedlove, D. \& Raven, P. (1974). Principles of Tzeltal plant classification. New York: Academic Press.

Bloch, M. \& Sperber, D. (2002) Kinship and evolved dispositions. Current Anthropology 43:723-748.

Bloch, M., Solomon, G. \& Carey, S. (2001). Zafimaniry: An Understanding of What is Passed on from Parents to Children: A Cross-Cultural Investigation. Journal of Cognition and Culture 1:43-68.

Bloom, P. \& Veres, C. (1999) The perceived intentionality of groups. Cognition 71:B1-B9.

Boster, J. \& Johnson, J. (1989). Form or function: A comparison of expert and novice judgments of similarity among fish. American Anthropologist 91:866-889.

Boster, J. \& D’Andrade, R. (1989). Natural and human sources of cross-cultural agreement in ornithological classification. American Anthropologist 91:132-142.

Boster, J., Berlin, B., \& O’Neill, J. (1986). The correspondence of Jivoroan to Scientific ornithology. American Anthropologist 88:569-583.

Brown, C. (1984). Language and living things: Uniformities in folk classification and naming. New Brunswick NJ: Rutgers University Press.

Brown, C., Kolar, J., Torrey, B., Truong-Quang, T. \& Volkman, P. (1976) Some general principles of biological and non-biological classification. American Ethnologist 3:73-85. 
Brown, D. \& Boysen, S. (2000) Spontaneous discrimination of natural stimuli by chimpanzees (Pan troglodytes). Journal of Comparative Psychology 114:392-400.

Bulmer, R. (1974) Folk biology in the New Guinea Highlands. Social Science Information 13:928.

Caramazza, A. (2002) The organization of conceptual knowledge: The view from neuropsychology. Paper presented to the British Academy Symposium on "Conceptual Knowledge,” June.

Carey S. (1985). Conceptual change in childhood. Cambridge, MA: Bradford Books.

Carey, S. (1995) On the origin of causal understanding. In D. Sperber, D. Premack \& A. Premack (Eds.), Causal cognition. Oxford: Clarendon Press.

Carey, S. (1999). The origin of concepts. Cambridge, MA: MIT Press.

Carey, S. (2003). The origin of concepts. Paper presented to the Joint Program Lecture Series in Culture and Cognition and Evolution and Human Adaptation. University of Michigan, Ann Arbor, February.

Carey, S., \& Diamond, R. (1977). From piecemeal to configurational representation of faces. Science 195:312-313.

Cerella, J. (1979) Visual classes and natural categories in the pigeon. Journal of Experimental Psychology Human perception and performance 5:68-77.

Chomsky, N. (2000). Minimalist Inquiries: The Framework. In R. Martin, D. Michaels \& J. Uriagereka (Eds.), Step by Step. Cambridge MA, The MIT Press 
Cohen, D. (2001).Cultural Variation: Considerations and Implications. Psychological Bulletin 127:451-471.

Coley, J., Medin, D., Proffitt, J., Lynch, E. \& Atran, S. (1999). Inductive reasoning in folkbiological thought. In Medin, D. \& Atran, S. (Eds.) Folkbiology. Cambridge, MA: MIT Press.

Coley, J., Medin, D. \& Atran, S. (1997) Does rank have its privilege? Inductive inferences in folkbiological taxonomies. Cognition 63:73-112.

Cosmides, L. \& Tooby, J. (1992) Cognitive adaptations for social exchange. In J. Barkow, L. Cosmides \& J. Tooby (Eds.), The adapted mind: Evolutionary psychology and the generation of culture. New York: Oxford University Press.

Csibra, G., Gergely, G., Bíró, S., Koós, O. \& Brockbank, M. (1999) Goal attribution without agency cues: The perception of 'pure reason' in infancy. Cognition 72:237-267.

Darwin, C. (1859) On the origins of species by means of natural selection. London: Murray.

Diamond, R., \& Carey, S. (1986). Why faces are and are not special: An effect of expertise. Journal of Experimental Psychology: General 115:107-117.

Donnellan, K. (1971) Necessity and criteria. In J. Rosenberg \& C. Travis (Eds.), Readings in the philosophy of language. Englewood-Cliffs, NJ: Prentice-Hall.

Dougherty, J. (1978) Salience and relativity in classification. American Ethnologist 5:66-80.

Dougherty, J. (1979) Learning names for plants and plants for names. Anthropological Linguistics 21:298-315. 
Eldredge, N. (1986) Information, economics, and evolution. Annual Review of Ecology and Systematics 17:351-369.

Ellen, R. (1993) The cultural relations of classification. Cambridge, UK: Cambridge University Press.

Fodor, Jerry (2000). The mind doesn't work that way: The scope and limits of computational Ppychology. Cambridge, MA: MIT Press.

Fodor, J. (1983) Modularity of mind. Cambridge, MA: MIT Press.

Gelman, S. \& Hirschfeld, L. (1999) How biological is essentialism? In D. Medin \& S. Atran (Eds.) Folkbiology. Cambridge, MA: MIT Press.

Gelman, S. \& Wellman, H. (1991) Insides and essences. Cognition 38:213-244.

Gelman, S. (2003). The essential child: Origins of essentialism in everyday thought. New York: Oxford University Press.

Ghiselin, M. (1981) Categories, life, and thinking. Behavioral and Brain Sciences 4:269-313.

Gil-White, F. (2001) Are ethnic groups biological "species" to the brain? Current Anthropology 42:515-554.

Goldstone, R. L. (1994). Influences of categorization on perceptual discrimination. Journal of Experimental Psychology: General 123:178-200.

Goldstone, R. L. (1998). Perceptual Learning. Annual Review of Psychology 49:585-612.

Griffiths, P. (in press) What is innateness? The Monist (special issue, ed. K Sterelny).

Guntheil, G., Vera, A., Keil, F. C. (1998). Do houseflies think? Patterns of induction and biological beliefs in development. Cognition 66:33-39. 
Hatano, G. \& Inagaki, K. (1999). A developmental perspective on informal biology. In D. L. Medin \& S. Atran (Eds.) Folk biology. Cambridge, MA: MIT Press.

Hatano, G. \& Inagaki, K. (In press) The formation of culture in mind: A sociocultural approach to cogntitve develoment. In J. Mehler, S. Carey \& L. Bonatti (Eds.) Cognitive development and conceptual change. Cambridge, MA : MIT Press.

Hauser, M. (2000) What animals really think. New York: Henry Holt \& Company.

Hauser, M., Chomsky, N. \& Fitch, W. T. (2002) The faculty of language. Science 298:15691578.

Hays, T. (1983) Ndumba folkbiology and general principles of ethnobotanical classification and nomenclature. American Anthropologist 85:592-611.

Heider, F. \& Simmel, S. (1944) An experimental study of apparent behavior. American Journal of Psychology 57:243-259.

Herrnstein, R. (1984) Objects, categories, and discriminative stimuli. In H. Roitblat (Ed.), Animal cognition. Hillsdale, NJ: Erlbaum.

Hickling, A. \& Gelman, S. (1995) How does your garden grow? Evidence of an early conception of plants as biological kinds. Child Development 66:856-876.

Hirschfeld, L. A. (1995). Do children have a theory of race? Cognition 54:209-252.

Hirschfeld, L. (1996) Race in the making. Cambridge, MA: MIT Press.

Hunn, E. (1977). Tzeltal folk zoology. NY: Academic Press.

Hunn, E. (1982) The utilitarian factor in folk biological clasification. American Anthropologist $84: 830-847$. 
Inagaki, K. (1990) The effects of raising animals on children's biological knowledge. British Journal of Developmental Psychology 8:119-129.

Inagaki, K. \& Hatano, G. (1993) Young children's understanding of the mind-body distinction. Child Development 64:1534-1549.

Inagaki, K. \& Hatano, G. (2001). Chidren's understanding of mind-body relationships. In M. Siegal and C. Peterson (Eds.), Children's Understanding of Biology and Health. Cambridge, UK: Cambridge University Press.

Johnson, S. \& Solomon, G. (1997) Why dogs have puppies and cats have kittens: The role of birth in young children's understanding of biological origins. $\underline{\text { Child Development }}$ 68:404419.

Johnson, K. \& Mervis, C. (1997). Effects of varying levels of expertise on the basic level of categorization. Journal of Experimental Psychology: General, 126: 248-277

Johnson, K., Mervis, C. \& Boster, J. (1992). Developmental changes within the structure of the mammal domain. Developmental Psychology 28:74-83.

Keil, F. (1979) Semantic and conceptual development. Cambridge, MA: Harvard University Press.

Keil, F. (1989) Concepts, kinds, and cognitive development. Cambridge MA: MIT Press.

Landa, Diego de (1985[1566]) Relación de la cosas de Yucatán, ed. M. Rivera Dorado. Crónicas de America, no. 7. Madrid: Historia 16.

Lévi-Strauss, C. (1962) Totemism. Boston: Beacon Press 
López, A., Atran, S., Coley, J., Medin, D., \& Smith, E. (1997) The tree of life: Universals of folk-biological taxonomies and inductions. Cognitive Psychology 32:251-295.

Lynch, E, Coley, J. \& Medin, D. (2000) Tall is typical: Central tendency, ideal dimensions and graded category structure among tree experts and novices. Memory \& Cognition 28:4150.

Mahalingam, R. (1998). Essentialism, power, and the representation of caste: A developmental study. PhD Thesis, University of Pittsburgh.

Malt, B. (1995). Category coherence in cross-cultural perspective. Cognitive Psychology 29:85148

Mandler, J., Bauer, P. \& McDonough, L. (1991) Separating the sheep from the goats: Differentiating global categories. Cognitive Psychology 23:263-298.

Mayr, E. (1982) The growth of biological thought. Cambridge, MA: Harvard University Press.

Medin, D. (1989) Concepts and conceptual structures. American Psychologist 45:1469-1481.

Medin, D., Coley, J., Storms, G. \& Hayes, B. (in press). A relevance theory of induction. Psychonomic Bulletin and Review.

Medin, D. \& Ortony, A. (1989) Psychological essentialism. In S. Vosniadou \& A. Ortony (Eds.), Similarity and analogical reasoning. New York: Cambridge University Press.

Medin, D., Ross, N., Atran, S., Burnett, R. \& Blok, S. (2002) Categorization and reasoning in relation to culture and expertise. In B. Ross (ed.), The psychology of learning and motivation: Advances in research and theory, Vol. 41. New York: Academic Press. 
von Neumann, J. \& Morgenstern, O. (1980) The theory of games. Princeton: Princeton University Press.

Nowak,M. \& Sigmund, K. (1998) Evolution of indirect reciprocity by image scoring. Nature $395: 573-577$.

Osherson, D., Smith, E., Wilkie, O., López, A., \& Shafir, E. (1990) Category-based induction. Psychological Review 97:85-100.

Pinker, S. (1997) How the mind works. New York: W.W. Norton.

Pinker, S \& Bloom, P. (1990) Natural language and natural selection. Behavioral and Brain Sciences 13:707-727.

Premack, D. (1990) The infant's theory of self-propelled objects. Cognition 36:1-16.

Proffitt, J., Coley, J. \& Medin, D. (2000). Expertise and Category - Based Induction. Journal of Experimental Psychology: Learning, Memory and Cognition 26:811-828.

Rips, L. (1975) Inductive judgments anoput natural categories. Journal of Verbal Learning and Verbal Behavior 14:665-681.

Rips, L (1995). The current status of research on concept combination. Mind \& Language 10:2104.

Rips, L. (2001). Necessity and natural categories. Psychological Bulletin 127:827-852.

Rosch E, \& Mervis, C. (1975). Family resemblances: Studies in the internal structure of categories. Cognitive Psychology 7:573-605.

Rosch, E., Mervis, C., Grey, W., Johnson, D., \& Boyes-Braem, P. (1976) Basic objects in natural categories. Cognitive Psychology 8:382-439. 
Ross, N., Medin, D., Coley, J. \& Atran, S. (in press). Cultural and Experiential Differences in the Development of Folkbiological Induction.Cognitive Development.

Sartori, G. \& Job, R. (1988) The oyster with four legs: A neuro-psychological study on the interaction of semantic and visual information. Cognitive Neuropsychology 5:105-132.

Schwartz, H. \& Medin, D. (2000). Expert and Novice Judgments of Inductive Inferences within Folk-biological taxonomies. Unpublished manuscript, Northwestern University.

Schyns, P. \& Rodet, L. (1997). Categorization creates functional features. Journal of Experimental Psychology: Learning, Memory and Cognition 23:681-696.

Schyns, P. , Goldstone, R. \& Thibaut, J. (1998). Development of features in object concepts. Behavioral and Brain Sciences 21:1-54.

Sloman, S. (1993) Feature-based induction. Cognitive Psychology 25:231-280.

Sloman, S. \& Malt, B. (in press). Artifacts are not ascribed essences, nor are they treated as blonging to kinds. Language and Cognitive Processes.

Smith, E. \& Medin, D. (1981) Categories and concepts. Cambridge, MA: Harvard University Press.

Smith, E., Shoben, E. \& Rips, L. (1974) Structure and process in semantic memory. Psychological Review 81:214-241.

Solomon, G., Johnson, S., Zaitchik, D. \& Carey, S. (1996) Like father, like son: Young children's understanding of how and why offspring resemble their parents. $\underline{\text { Child }}$ Development 67:151-171. 
Sousa, P., Atran, S., and Medin, D. (2002). Essentialism and folkbiology: Further evidence from Brazil. Journal of Cognition and Culture 2:195-203.

Sperber, D. (2001) In defense of massive modularity. Paper presented to the "Innateness and Structure of the Mind” Workshop, University of Sheffield, November.

Sperber, D., Cara, F. \& Girotto, V. (1995) Relevance theory explains the selection task. Cognition 57:31-95.

Stoler, A. (1995). Race and the Education of Desire. Durham, NC: Duke University Press.

Strevens, M. (2000) The naïve aspect of essentialist theories. Cognition 74:149-175.

Stross, B. (1973) Acquisition of botanical terminology by Tzeltal children. In M. Edmonson (Ed.), Meaning in Mayan languages. The Hague: Mouton.

Swinney, D. (1981). Lexical Processing during Sentence Comprehension: Effects of higher order constraints and implications for representation. In T. Meyers, J. Laver \& J. Anderson (Eds.), The Cognitive Representation of Speech, Amsterdam: North-Holland Publishing Co. (Advances in Psychology Series).

Tanaka, J. \& Taylor, M. (1991). Object categories and expertise: Is the basic level in the eye of the beholder? Cognitive Psychology 23: 457-482.

Trager, G. (1939) "Cottonwood" = "tree": A southwestern linguistic trait. International Journal of American Linguistics 9:117-118.

Waddington, C. (1959) Canalisation of development and the inheritance of acquired characteristics. Nature 183:1654-1655. 
Walker [Jeyifous], S. (1992) Supernatural beliefs, natural kinds and conceptual structure. Memory \& Cognition 20:655-662.

Waxman, S. (1999). The dubbing ceremony revisited: Object naming and categorization in infancy and early childhood. In D. Medin \& S. Atran (Eds.), Folkbiology. Cambridge, MA: MIT Press.

Waxman, S., \& Markow, D. (1995). Words as invitations to form categories: Evidence from 12month-old infants. Cognitive Psychology 29:257-302.

Wolff, P., Medin, D. \& Pankratz, C. (1999) Evolution and devolution of folkbiological knowledge. Cognition 73:177-204.

Zubin, D. \& Köpcke, K.-M. (1986) Gender and folk taxonomy. In C. Craig (Ed.), Noun classes and categorization. Amsterdam: John Benjamins. 
Table 1: Empirical and theoretical claims and the status of evidence bearing on them.

Claim:

\begin{tabular}{|l|l|}
\hline Essentialism is a universal bias. & $\begin{array}{l}\text { Inductive generalization over several } \\
\text { populations but needs further case studies. }\end{array}$ \\
\hline $\begin{array}{l}\text { Essence and inductively privileged } \\
\text { species (e.g. robin) not lifeform } \\
\text { (e.g. bird) }\end{array}$ & $\begin{array}{l}\text { Appears to hold across a variety of } \\
\text { level corresponds to generic populations } \\
\text { but needs further case studies. }\end{array}$ \\
\hline $\begin{array}{l}\text { Basis for typicality ratings and typicality } \\
\text { effects in reasoning knowledge-dependent } \\
\text { and undergraduates are often the "odd- } \\
\text { group out" }\end{array}$ & $\begin{array}{l}\text { Itza' Maya, bird experts, fish experts and } \\
\text { tree experts differ from undergraduates. }\end{array}$ \\
\hline $\begin{array}{l}\text { Standard populations (e.g.undergraduates) } \\
\text { may use impoverished default } \\
\text { categorization and reasoning } \\
\text { strategies (e.g. abstract similarity } \\
\text { judgments) relative to those } \\
\text { used by most of humanity (e.g. } \\
\text { content-rich strategies) }\end{array}$ & $\begin{array}{l}\text { Substantial within the domain of } \\
\text { folkbiology. An open issue for other } \\
\text { domains. }\end{array}$ \\
\hline $\begin{array}{l}\text { Children's folk biology is distinct from } \\
\text { folk psychology and not anthropocentric }\end{array}$ & $\begin{array}{l}\text { Supported in Maya, Menominee, and Rural } \\
\text { majority culture populations }\end{array}$ \\
\hline $\begin{array}{l}\text { Folkbiology represents an innate module, } \\
\text { with coherent variation as a function of } \\
\text { culture and expertise. }\end{array}$ & $\begin{array}{l}\text { Framework useful; results only partially } \\
\text { predicted in advance. }\end{array}$ \\
\hline
\end{tabular}


Table 2. Percent birth parent choice for Brazilian children (after Sousa et al. 2002).

\begin{tabular}{|c|l|l|l|l|l|l|}
\hline & $\begin{array}{c}\text { K NOWN } \\
\text { BEHAV }\end{array}$ & $\begin{array}{c}\text { K NOWN } \\
\text { TRAIT }\end{array}$ & $\begin{array}{c}\text { UNKNOWN } \\
\text { BEHAV }\end{array}$ & $\begin{array}{c}\text { UNKNOWN } \\
\text { TRAIT }\end{array}$ & BLOOD & CONTROL \\
\hline $\begin{array}{c}4 \text { year } \\
\text { olds }\end{array}$ & $0.87 * * *$ & $0.87 * * *$ & $0.78 * *$ & $0.83 * *$ & 0.33 & $0.13 * * *$ \\
\hline $\begin{array}{c}5 \text { year } \\
\text { olds }\end{array}$ & $0.92 * * *$ & $0.96 * * *$ & $0.78 * *$ & $0.87 * * *$ & $0.25 *$ & $0.00 * * *$ \\
\hline $\begin{array}{c}6 \text { year } \\
\text { olds }\end{array}$ & $0.71 *$ & $0.87 * *$ & $0.71 *$ & $0.75 *$ & $0.26 *$ & $0.04 * * *$ \\
\hline $\begin{array}{c}7 \text { year } \\
\text { olds }\end{array}$ & $0.83 * *$ & $0.83 * *$ & $0.79 * *$ & $0.83 * *$ & 0.35 & $0.00 * * *$ \\
\hline Adults & $1.00 * * *$ & $1.00 * * *$ & $0.83 * *$ & $0.87 * * *$ & $0.96 * * *$ & $0.00 * * *$ \\
\hline
\end{tabular}

$\mathrm{p}<.05 *, \mathrm{p}<.01 * *, \mathrm{p}<.001 * * *$ 


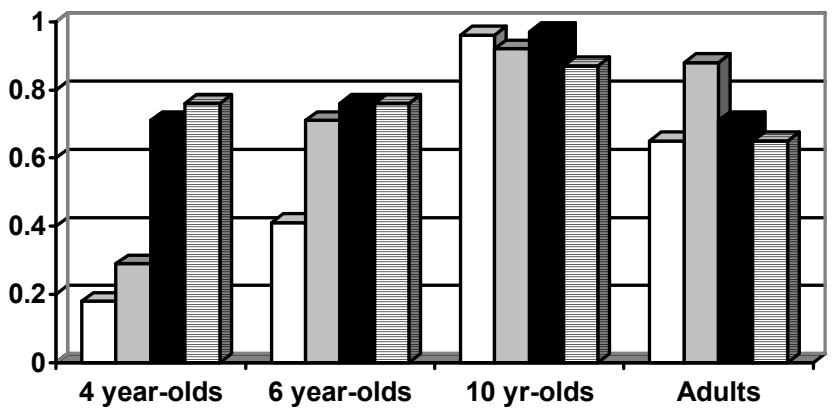

口Dog->human

口Dog->aardvark

Duman->dog

目Human->aardvark

Figure 1. Urban USA subjects' willingness to project unknown biological properties (after Carey 1985)

Figure 2

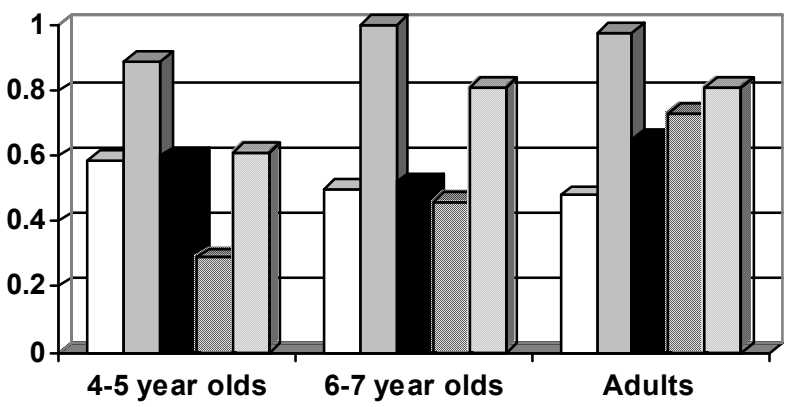

$\square$ Dog->human

$\square$ Dog->mam mal

- Hum an->mam mal

$\checkmark$ Peccary->human

$\square$ Peccary->mammal

Figure 2. Yukatek Maya subjects' willingness to project unknown biological properties (after Atran et al. 2001) 
Figure 3. Yukatek Maya Projections from Human

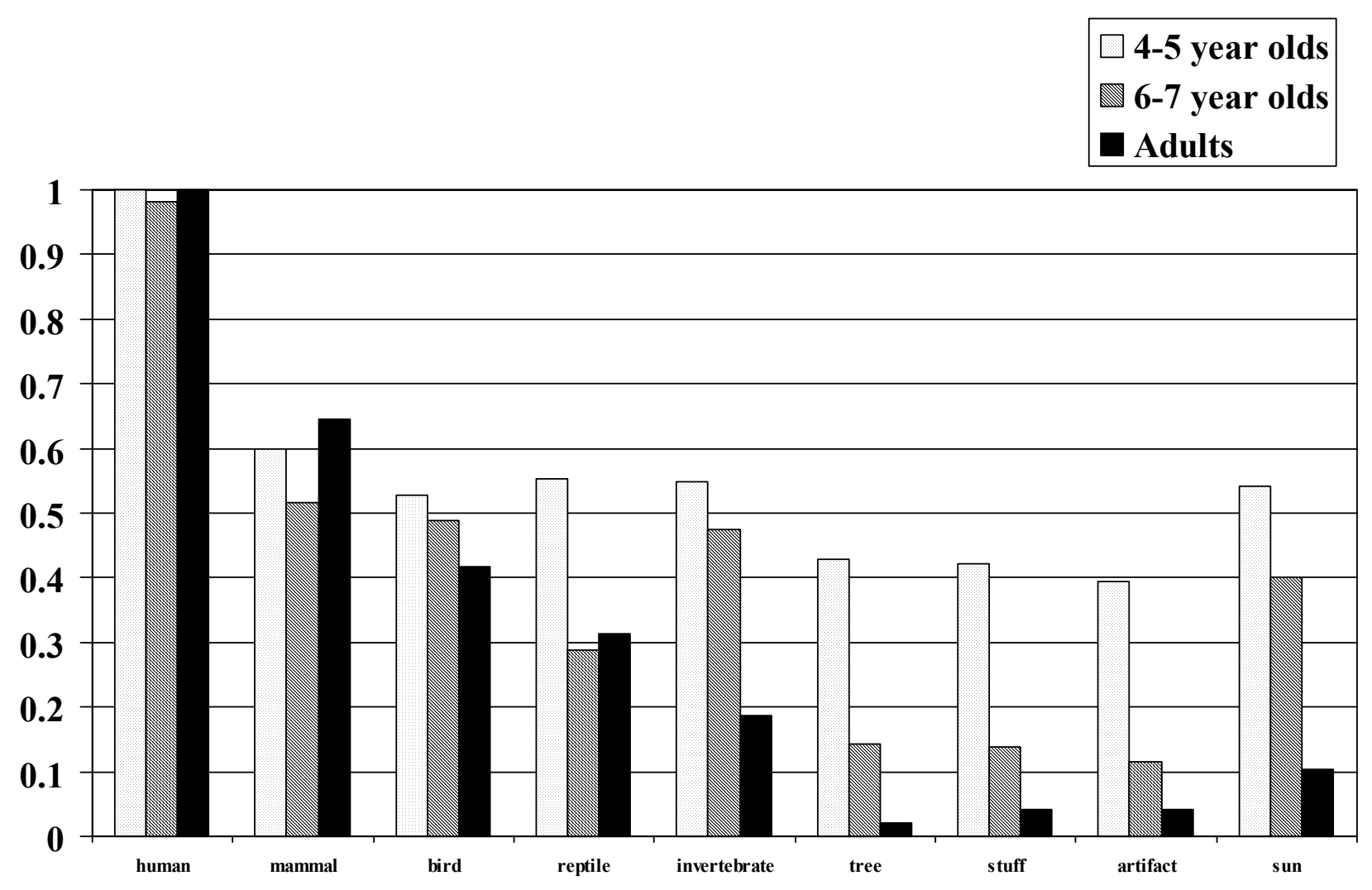


Figure 4. Inductive Inferences for Itza' Maya and USA students compared (after Coley et al. 1997).

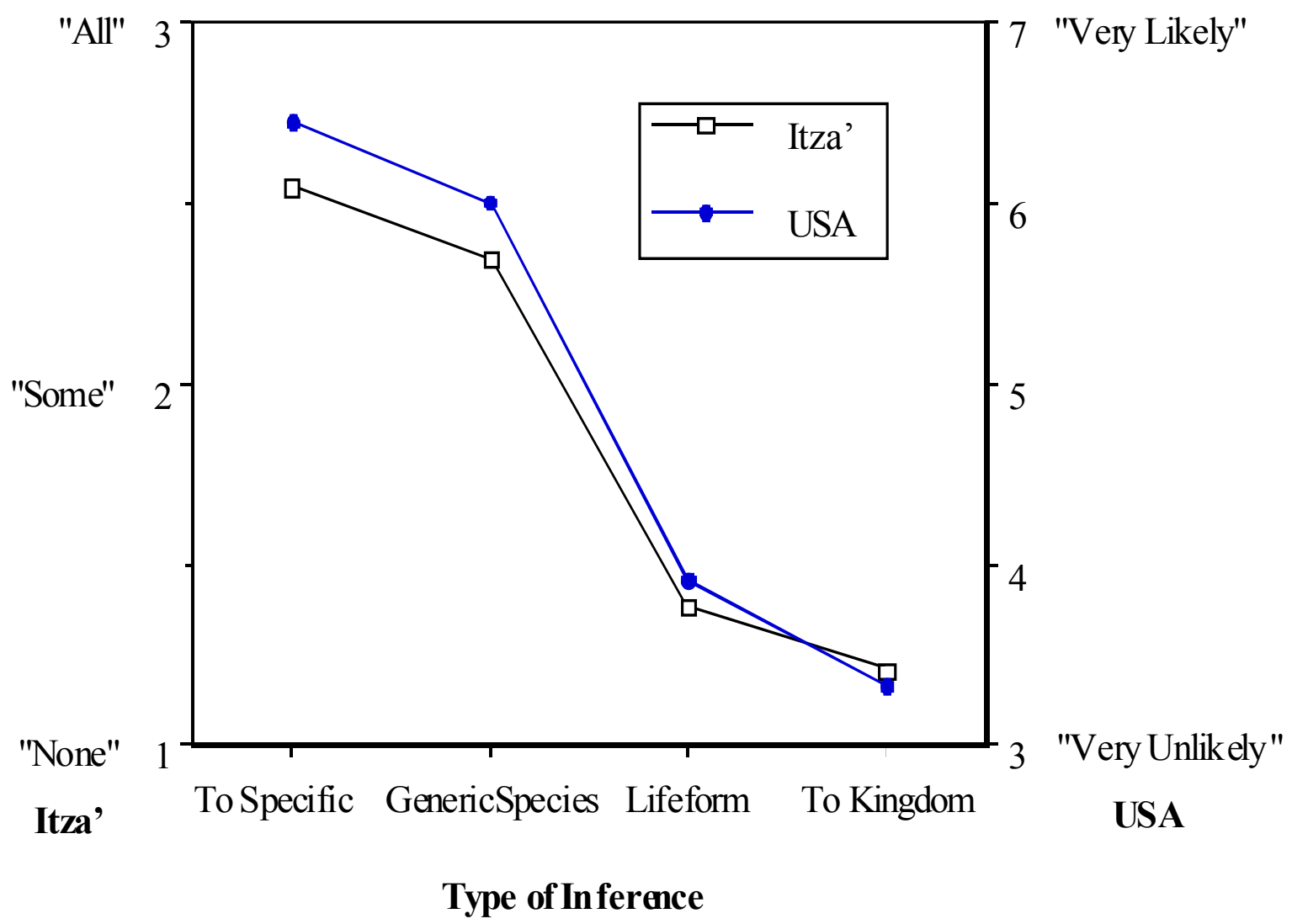


Figure 5. Proportion of quotations in the OED for different levels of specificity along with associated 95\% confidence intervals (after Wolff et al. 1999). Note that before ca.1700 folk "generic" terms (e.g. "oak," "bear") referred mostly to monogeneric European species, whereas after ca. 1700 generic terms often referred to polytypic species built around a European type.

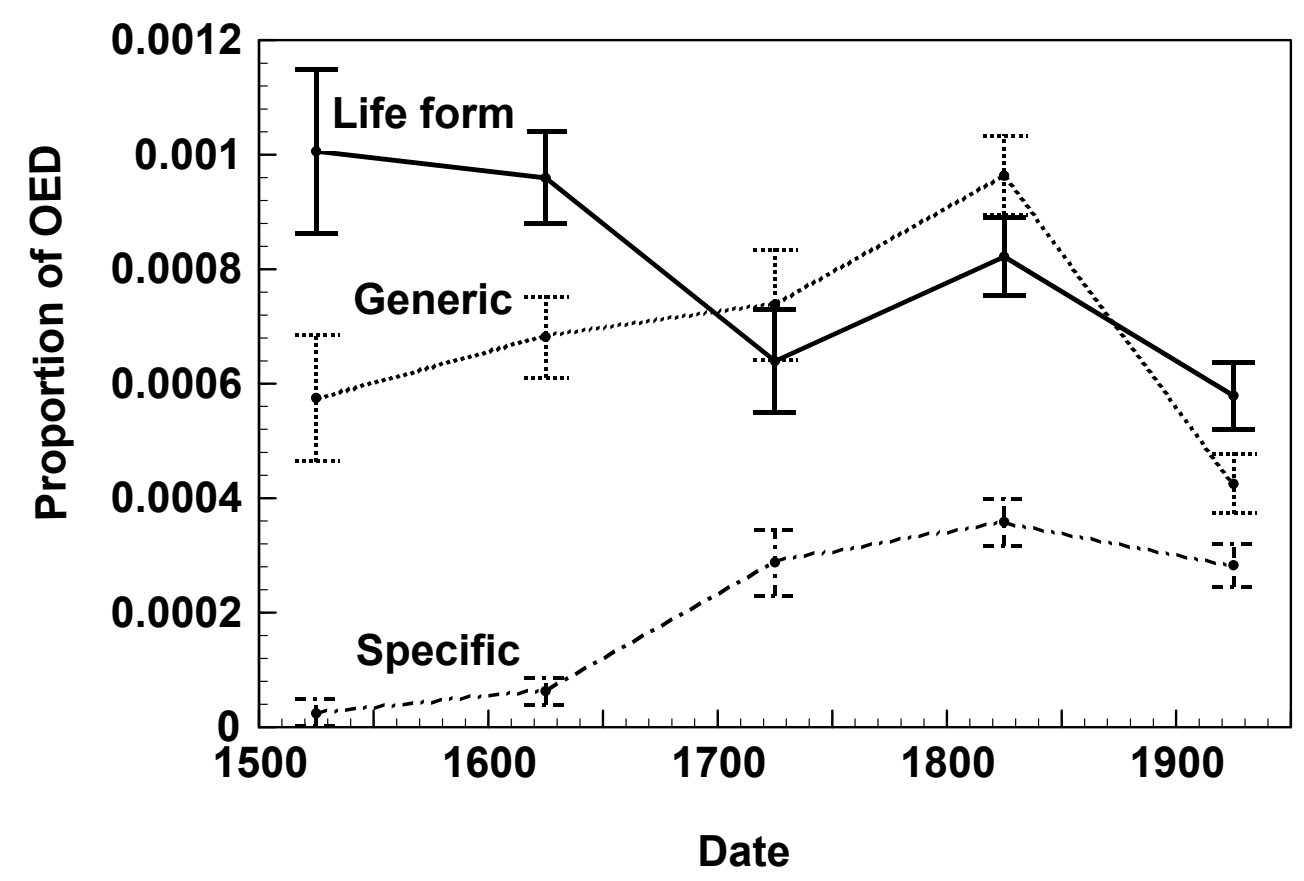




\section{Notes}

${ }^{1}$ This excludes - perhaps artificially - "lower-order" cognitions related to sex, kinship and violence.

${ }^{2}$ Phylogenetic comparisons of humans with other primates show some evidence for rudimentary forms biological conceptualization of species differences. For example, vervet monkeys have distinct alarm calls for different predator species or groups of species: snake, leopard and cheetah, hawk, eagle, and so forth (Hauser, 2000). Chimpanzees may even have rudimentary hierarchical groupings of biological groups within groups (Brown \& Boysen, 2000). Only humans, however, appear to have a concept of (folk) species as such, as well as taxonomic rankings of relations between species.

${ }^{3}$ For Fodor (2000), the primary criterion for modularity is "encapsulation," that is, exclusive access to a proprietary input. Encapsulation is supposedly true only of perceptual modules, such as language or facial recognition. In ordinary circumstances, internal principles of grammar, phonetic rules and lexical structures provide a database for rapidly processing linguistic input with practically no regard for, or influence from, other cognitive systems. Similarly, folkbiological taxonomy arguably provides a privileged database for nearly "automatic" recognition of plant and animal exemplars in terms of the (folk) species to which they uniquely belong. Of course, almost by definition any conceptual system has some functional autonomy and is therefore "encapsulated." Virtually any game (e.g., chess) or routine activity (e.g., car driving) relies on a restricted database that gives it privileged access to a certain range of input. This would seem to trivialize the notion of modularity and rob it of any descriptive or explanatory force. Indeed, according to Fodor (2000:23), the best case that can be made for the computational theory of mind (i.e., the view that all conceptual processes are Turing-like 
computations over syntactic-like representational structures) is in terms of conceptual modularity; however, because conceptual modularity "is pretty clearly mistaken," then so very likely is the claim that the computational theory of mind has very much to tell us about how the mind configures the world. For Sperber (2001), Fodor's pessimism is unwarranted because it ignores the fact that privileged access to an input set depends on the competition for mental resources. Evolutionary task demands generally favor certain naturally-selected modular structures for processing certain types of naturally recurrent and statistically relevant input (all other things being equal). In principle, then, an explanatory account of modularity in terms of evolutionary task demands and related developmental considerations of modularity is preferable to a purely descriptive account in terms "encapsulation," "mandatoriness" and the like.

${ }^{4}$ Paul Griffiths (in press) argues that because the items on any such symptomatic list don't necessarily co-occur in any given case, and can't unequivocally demonstrate innateness, then notions of innateness are inherently confused and should be discarded. The same could be said against modularity. But the list represents only a family of evidential heuristics, and does not pretend to be a causal analysis of innateness or modularity.

${ }^{5}$ Still other characteristics may be explained in terms of individual, random variation; however, our use of paired category-typical characteristics minimize this eventuality.

${ }^{6}$ In another study, however, Gelman and Wellman (1991) asked children to reason about plants without identifying the species membership. For example, they described a seed that came from an apple and was planted in a field a corn, without identifying the seed as "an apple seed." The results were largely the same as with the animals and supported a nature over nurture bias (cf. Hickling \& Gelman, 1995, and Gelman, in press). 
${ }^{7}$ For example, in Brazil, several of the 6-7 year-old children based their responding on an explicit analogy with the Disney movie, Tarzan, which was widely shown at the time of the study. They evinced a significant but weaker birth bias than 4-5 year-olds, consistent with Tarzan's mixed human/ape behavioral characteristics.

${ }^{8}$ Barsalou (1985) argued that idealness rather than central tendency predicts typicality in goalderived categories (e.g., foods not to eat on a diet, things to take from one's home during a fire, camping equipment), although central tendency still supposedly predicts typicality in "taxonomic" categories (furniture, vehicles), including folkbiological categories (birds).

${ }^{9}$ At the time this study was conducted we thought that we were observing central-tendency based typicality effects but we realized later that typicality in this sense was confounded with typicality based on ideals. Later studies (to be described shortly) suggest that idealness is the key factor. 